Review article

\title{
Trends and strategies to enhance triacylglycerols and high-value compounds in microalgae
}

\author{
Lisa M. Schüler ${ }^{a}$, Peter S.C. Schulze ${ }^{a, b}$, Hugo Pereira ${ }^{a}$, Luísa Barreira ${ }^{a}$, Rosa León ${ }^{c}$, João Varela ${ }^{a}, *$ \\ a Centre of Marine Sciences, University of Algarve, Campus de Gambelas, 8005-139 Faro, Portugal \\ b Faculty of Biosciences and Aquaculture, Nord University, 8049 Bodø, Norway \\ ${ }^{\mathrm{c}}$ Laboratory of Biochemistry, Faculty of Experimental Sciences, Marine International Campus of Excellence (CEIMAR) and CEICAMBIO, University of Huelva, Huelva, \\ Spain
}

\section{A R T I C L E I N F O}

\section{Keywords:}

TAG

Carotenoids

Long-chain polyunsaturated fatty acids

Microalgae

Biotechnology

Stressors

\begin{abstract}
A B S T R A C T
Microalgae are important sources of triacylglycerols (TAGs) and high-value compounds such as carotenoids and long-chain polyunsaturated fatty acids (LC-PUFAs). TAGs are feedstocks for biofuels or edible oils; carotenoids are used as pigments in the food and feed industries; and LC-PUFAs are beneficial for human health, being also key to the correct development of fish in aquaculture. Current trends in microalgal biotechnology propose the combined production of biofuels with high-value compounds to turn large-scale production of microalgal biomass into an economically feasible venture. As TAGs, carotenoids and LC-PUFAs are lipophilic biomolecules, they not only share biosynthetic precursors and storage sinks, but also their regulation often depends on common environmental stimuli. In general, stressful conditions favor carotenoid and TAGs biosynthesis, whereas the highest accumulation of LC-PUFAs is usually obtained under conditions promoting growth. However, there are known exceptions to these general rules, as a few species are able to accumulate LC-PUFAs under low light, low temperature or long-term stress conditions. Thus, future research on how microalgae sense, transduce and respond to environmental stress will be crucial to understand how the biosynthesis and storage of these lipophilic molecules are regulated. The use of high-throughput methods (e.g. fluorescent activated cell sorting) will provide an excellent opportunity to isolate triple-producers, i.e. microalgae able to accumulate high levels of LC-PUFAs, carotenoids and TAGs simultaneously. Comparative transcriptomics between wild type and tripleproducers could then be used to identify key gene products involved in the regulation of these biomolecules even in microalgal species not amenable to reverse genetics. This combined approach could be a major step towards a better understanding of the microalgal metabolism under different stress conditions. Moreover, the generation of triple-producers would be essential to raise the biomass value in a biorefinery setting and contribute to meet the world's rising demand for food, feed and energy.
\end{abstract}

1. Commercial available species of microalgae and their evolutionary relationships

Phototrophic microalgae are of great interest as microscopic factories for the production of biomolecules for the energy and added-value compound markets. Compared with terrestrial plants, microalgae do not compete with crop plants for arable land. In addition, they have higher areal productivities, in some cases 20 times higher than those of terrestrial plants [1], thus being a good alternative feedstock for feed, food and fuel. Only about 20 species are currently commercialized, mainly belonging to the unranked Stramenopiles/ Haptista lineages or to Archaeplastida [2]. Most prominent candidates of the Stramenopiles/Haptista lineages (Fig. 1) include the genera
Nannochloropsis and Phaeodactylum due to their high contents of the long-chain polyunsaturated fatty acids (LC-PUFAs) eicosapentaenoic (EPA) and docosahexaenoic (DHA) acids. These important microalgalbased $\omega$-3 fatty acids find their applications in aquaculture, animal feed and nutraceutical industry and can replace those obtained from fish meal or oils. Furthermore, microalgae of the Archaeplastida lineage produced industrially are usually chlorophytes, such as Dunaliella, Haematococcus and Chlorella. These algae are rich in the carotenoids $\beta$-carotene, astaxanthin and canthaxanthin used as pigments in food and feed [3]. Microalgae are also source of other carotenoids such as lutein and fucoxanthin which are utilized as antioxidants. Although, there have been efforts to use microalgal triacylglycerols (TAGs) as feedstock for biofuels, there is a current trend in microalgal research to

\footnotetext{
* Corresponding author.

E-mail address: jvarela@ualg.pt (J. Varela).
} 


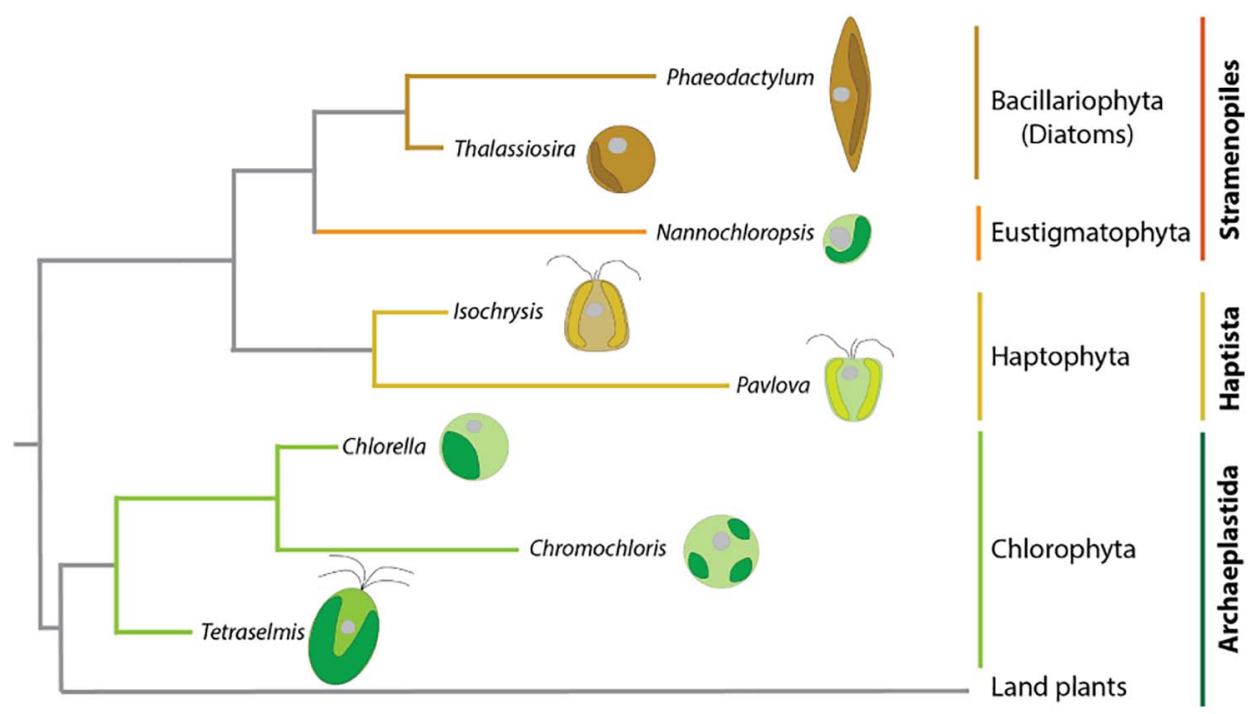

Fig. 1. Evolutionary relationships of target microalgal lineages for combined production of TAGs, LC-PUFAs and carotenoids. Branch length does not represent distance values. Adapted from Burki et al. [2]).

combine the biosynthesis of LC-PUFA-rich TAGs with the accumulation of other high-valuable lipophilic compounds, such as carotenoids. In this sense, microalgal TAGs would be used as edible oil in food and feed applications as well as a vehicle for carotenoids.

The production of large amounts of TAGs, LC-PUFAs and carotenoids by microalgae depends on the species and growth conditions. Environmental stimuli such as nutrient availability, light intensity and temperature, among other factors, further increase the accumulation of TAGs and high-value compounds as a response to unfavorable growth conditions, thus leading to improved survival of the microalgal cell. Nevertheless, the biosynthesis, signaling pathways and mechanisms responsible for their accumulation are not yet fully understood [4].

This review focuses on the microalgal production of TAGs, LCPUFAs and carotenoids as well as methodologies promoting their accumulation and pathways involved in the biosynthesis of these high-value biomolecules and lipids. Even though several reviews on each class of biochemicals have been published [5-11], to the best of our knowledge a discussion on how the combined production of all three could be achieved in the same microalga is lacking. As these three classes of compounds can be considered to be lipids or lipophilic molecules, they share biosynthetic precursors, common environmental stimuli and accumulate in lipophilic "sinks", such as lipid droplets and bilayers. Results from various studies using environmental factors for the induction of the three compounds are summarized. For each biomolecule class, induction methodologies are compared and the most promising species to become triple-producers are indicated. We further provide an overview of current and future strategies to improve TAGs, LC-PUFAs and carotenoid production via the selection of promising target species and high-throughput isolation of naturally occurring mutants thereof. Knowledge gaps are discussed and future lines of research for the improvement of the biotechnological applications of microalgae are suggested.

\section{General views of lipid metabolism of microalgae}

Microalgal lipids can be classified as polar (e.g. phospho- and glycolipids) and neutral or non-polar (e.g. TAGs, sterols and waxes) [12]. The assembly of polar lipids and TAGs can occur in the chloroplast envelope or at the ER membrane, depending on the microalgal species (Fig. 2). Polar lipids usually accumulate in membranes, such as the plasma, ER and thylakoid membranes, as well as the inner and outer membranes of the chloroplast and mitochondria, whereas TAGs are often deposited in plastidial or cytosolic lipid droplets. Both polar lipids and TAGs can be composed of LC-PUFAs that are synthesized at the ER by specific desaturases and elongases (Fig. 2). Nevertheless, TAGs usually have high levels of saturated and monounsaturated fatty acids to maximize molecule packing, whereas membrane lipids tend to contain higher contents of LC-PUFAs $[13,14]$.

Even though the exact topology of the enzymes involved in carotenoid biosynthesis has not been fully elucidated, it is often surmised that carotenoids are synthesized in the lipid compartment (Fig. 2). Based on studies in land plants and microalgae, the biosynthesis of carotenoids can occur in several places in the chloroplast, namely the plastidial envelope, plastoglobuli and thylakoid membranes, which might also depend on the function of the synthesized carotenoids [15]. For example, in Dunaliella salina var. bardawil, it has been proposed that $\beta$-carotene can be synthesized in the plastidial envelope as well as in plastoglobuli [16]. Furthermore, carotenoids are a very diverse group of 40-carbon isoprenoid biomolecules with $>750$ structures and different functions, whose biosynthetic pathways may occur in a given microalgal lineage and be partially absent in another [6]. The xanthophylls (i.e. oxygen-containing carotenoids) astaxanthin and lutein occur mainly in Archaeplastida, whereas fucoxanthin and vaucheriaxanthin are mainly present in Stramenopiles/Haptista microalgae; $\beta$-carotene can be found in all three major microalgal lineages [17].

\section{Induction of biosynthesis and accumulation of TAGs, LC-PUFAs or carotenoids in microalgae}

Under optimal growth conditions microalgae are able to display fast growth rates with doubling times as low as $10 \mathrm{~h}$ (e.g. Chlamydomonas reinhardtii [18]), producing biomass with low amounts of lipids. However, under sup-optimal growth conditions algae tend to accumulate neutral lipids, carbohydrates and/or carotenoids and are thus able to adapt to environmental extremes. The biosynthesis and accumulation of specific compounds depend, however, on the genetics of the microalgal species, growth phase, nutrient availability, salinity, temperature and irradiation. The research focusing on how TAGs, carotenoids and LC-PUFAs can be induced rests heavily on the evolutionary lineage of the microalga under study. Recent trends indicate that Stramenopiles microalgae (e.g. Nannochloropsis) are often researched for their TAGs and LC-PUFAs content, whereas chlorophytes (e.g. Chlorella) are the target of most reports on TAGs and carotenoids. 


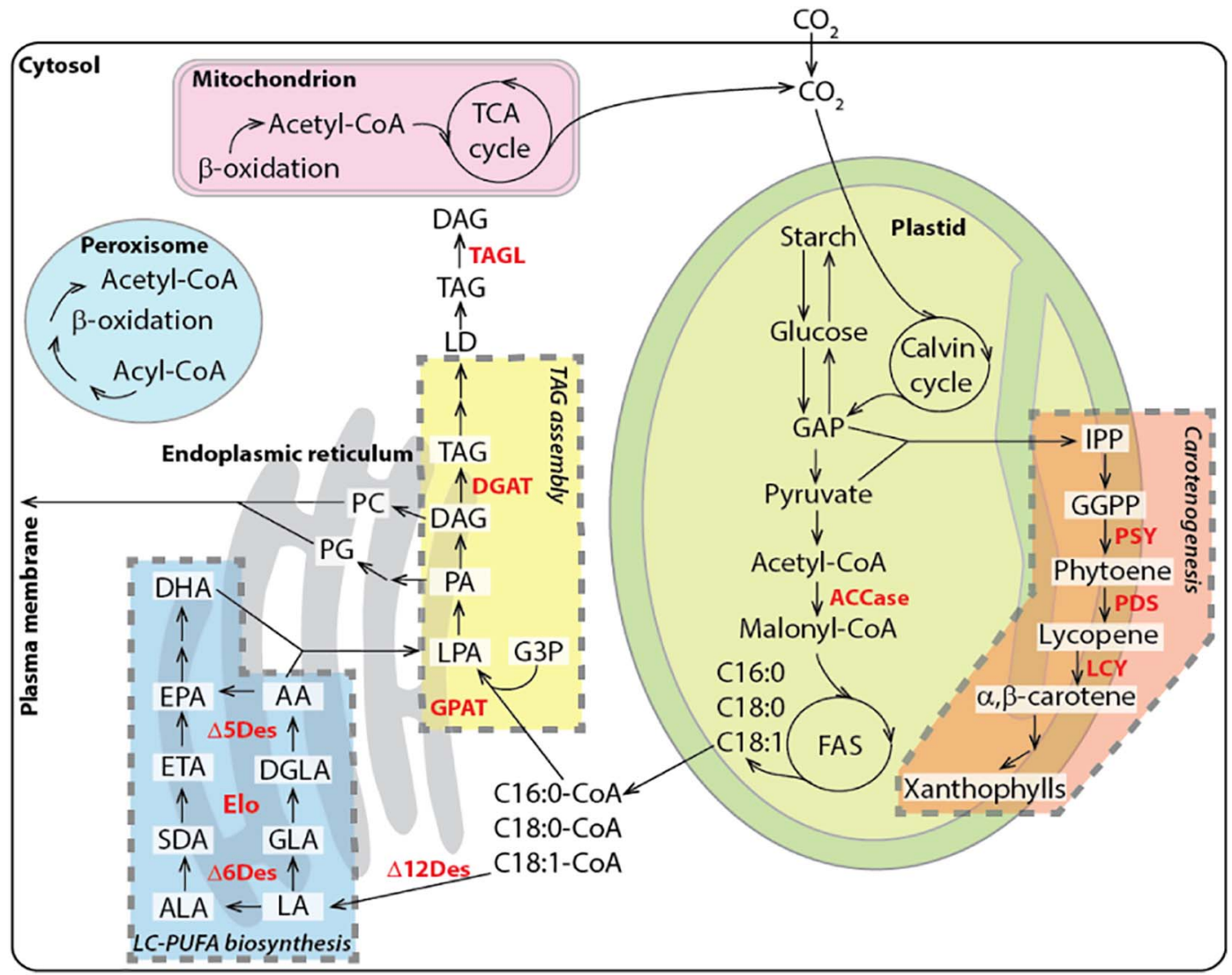

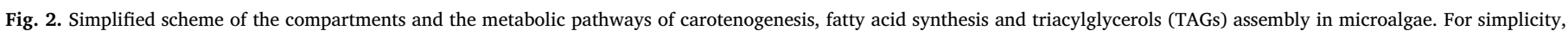

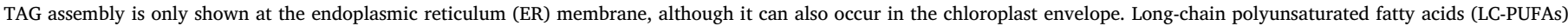

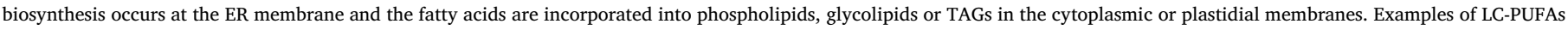

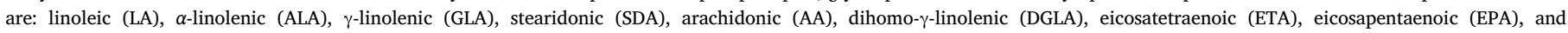

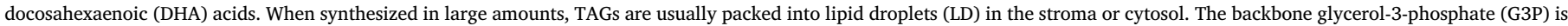

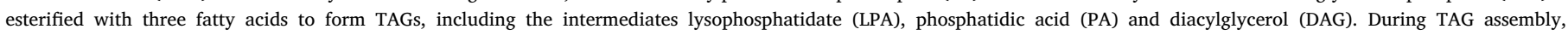

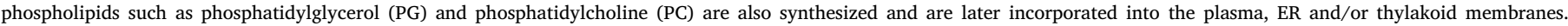

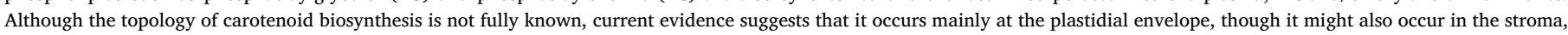

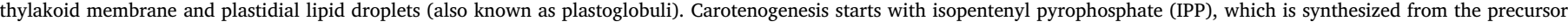

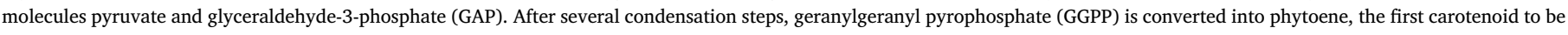

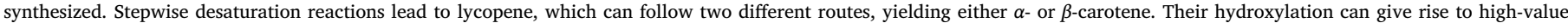

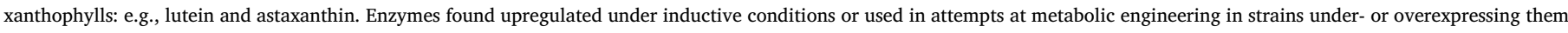

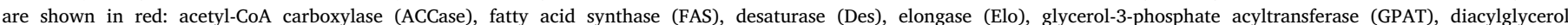

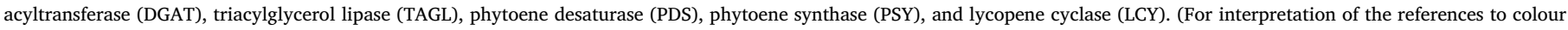
in this figure legend, the reader is referred to the web version of this article.)

\subsection{TAG induction}

Microalgae such as Chlorella vulgaris, Chromochloris (syn. Chlorella) zofingiensis, Chlorococcum littorale, Nannochloropsis oceanica, Neochloris oleoabundans and Scenedesmus obliquus are able to accumulate large amounts of TAGs under stress conditions. A common trigger is nutrient depletion, which also occurs upon entry into stationary phase. These non-optimal conditions lead to decreased cell growth and proliferation. In turn, this may entail a lower need for membrane lipids and a larger amount of fatty acids being diverted to TAG assembly $[4,19,20]$.

Apart from being a mechanism of carbon and energy storage, TAG biosynthesis and assembly might have additional functions [21]. In photosynthetic organisms, the energy of photons captured by the photosystems or associated antennae provide electrons able to reduce $\mathrm{NADP}^{+}$to NADPH. The reduced form of this electron carrier is then oxidized by biosynthetic pathways, becoming available to photosynthesis once again. As the biosynthesis of lipids requires roughly the double amount of NADPH than that of protein or carbohydrates, pathways leading to TAG accumulation might therefore protect microalgal cells from excess electrons produced under stress conditions. This can take place when the capacity of the photosynthetic electron transport chain is exceeded and electrons accumulate, resulting in the generation of reactive oxygen species (ROS). Although ROS are constantly produced in the cell and may have an important function as signaling molecules [22], an imbalance of ROS can lead to oxidative stress resulting in damage of photosystems and oxidation of DNA, protein and lipids.

Regardless of the evolutionary lineages, nitrogen depletion was the most tested induction technique with an up to 20 -fold increase (Fig. 3), leading to contents as high as 45\% TAGs of dry weight (DW) after starving $C$. vulgaris for 14 days [23]. Other species accumulating high amounts of TAGs (35-42\% of DW) under nitrogen depletion are $N$. oleoabundans, C. zofingiensis, C. littorale, S. obliquus, Nannochloropsis gaditana and N. oceanica [23-27]. For some microalgae (e.g. Nannochloropsis oculata and C. zofingiensis), TAG content was improved from 32 to $40 \%$ TAGs of DW by exposing them to higher light intensities (250-350 $\mu \mathrm{mol} \mathrm{m}^{-2} \mathrm{~s}^{-1}$ ) [28,29].

The existence of common inducers for TAGs in microalgae of different lineages could be the result of the conservation of the TAG assembly pathway. As a matter of fact, genes coding for key enzymes of the TAG assembly (e.g. acyltransferases) resembling those present in plant cells are also found in microalgae [4]. This assertion can be 

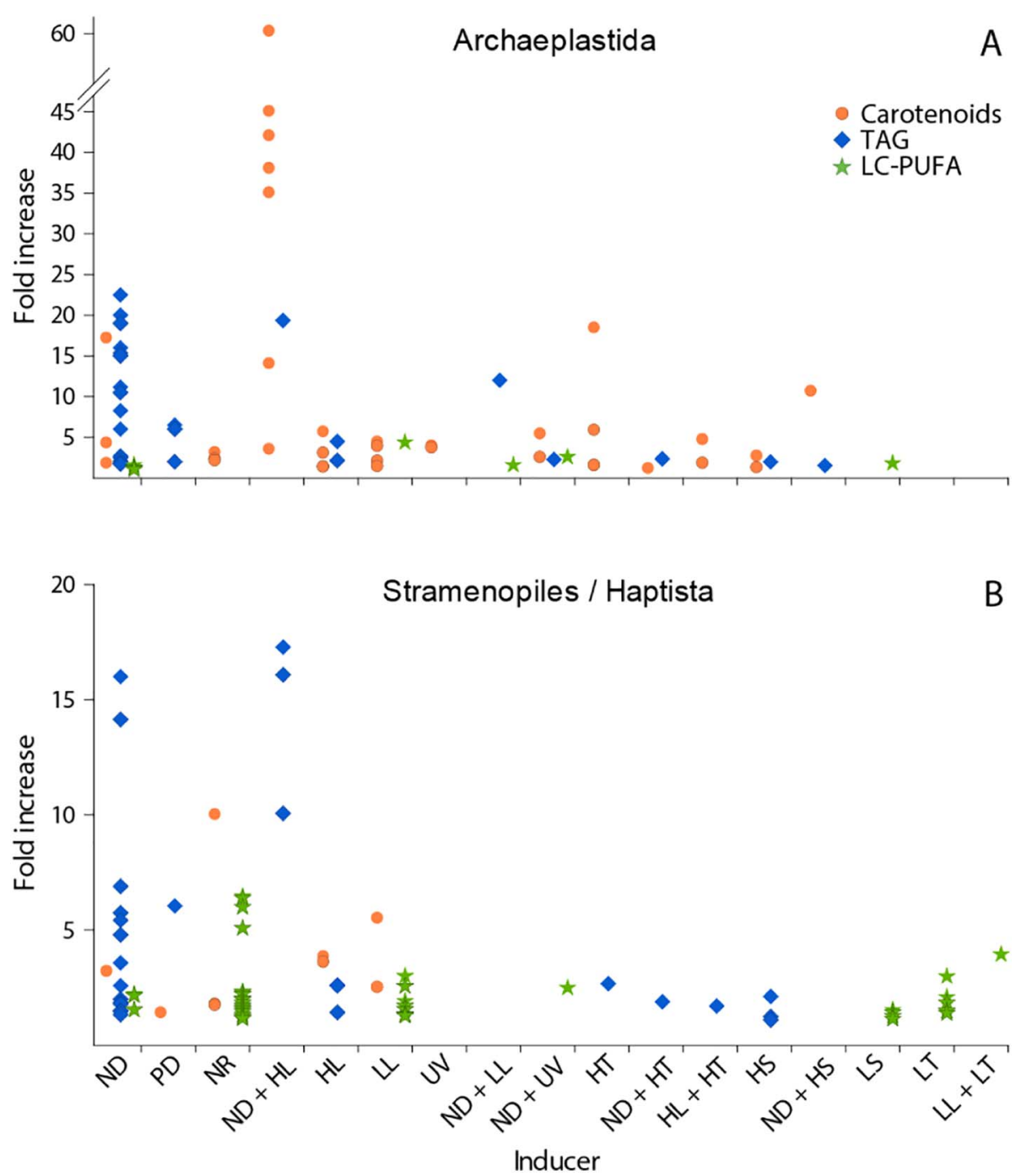

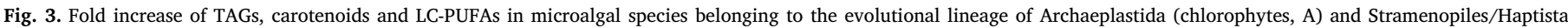

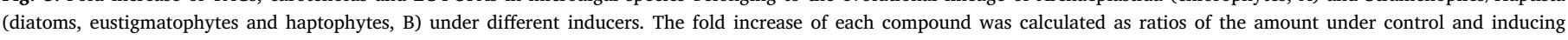

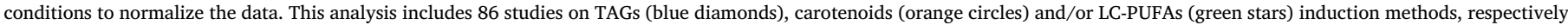

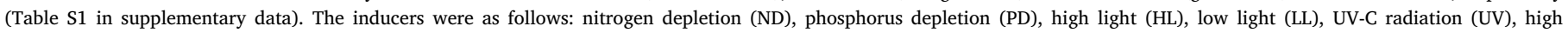

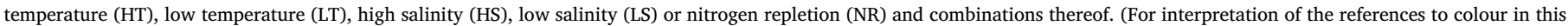
figure legend, the reader is referred to the web version of this article.)

supported by studies showing the upregulation of diacylglycerol acyltransferase (DGAT), an enzyme catalyzing the last step of the TAG assembly, in $C$. reinhardtii and $N$. oceanica under nitrogen starvation (Fig. 2). Under nitrogen starvation and high light, the NADPH levels as well as the enzymatic activity of DGAT and acylCoA carboxylase (ACCase) increase [29]. Hence, besides TAG assembly, fatty acid biosynthesis appears to be induced by these two stressors as well. Nevertheless, the effectiveness of nitrogen depletion as inducer of TAGs and fatty acid biosynthesis is species- and also time-dependent. Furthermore, phosphorus depletion has also been shown to be an efficient inducer of TAG biosynthesis in Scenedesmus sp., Monodus subterraneus and $C$. vulgaris, though yielding a more modest increase ( $\approx 6$-fold) as compared to that obtained under nitrate depletion (Fig. 3) [30-33]. In fact, depletion of nutrients is one of the preferred triggers of TAG accumulation, as a decrease in nutrient levels added to cultures can significantly reduce costs in large-scale processes.

High salinity leads to oxidative stress, a condition that has been described to induce the accumulation of lipids in both freshwater and marine microalgae, probably as a response to an unfavorable environment for growth and the need for storing energy-rich compounds to be able to survive to a harsher environment [34]. However, further research on the mechanisms of lipid upregulation under high salinity is still needed. The marine species Nannochloropsis salina and Dunaliella tertiolecta accumulated double the amount of TAGs under growth in high salinities of 58 ppt compared to 29 ppt $[35,36]$. In Scenedesmus sp., a salinity shift from freshwater to 23 ppt resulted in a TAG content of $25 \%$ of DW, whereas under nitrogen depletion TAGs were accumulated up to $38 \%$ of DW $[23,34]$. Thus, salinity as inducer of TAG accumulation is apparently not as efficient as nutrient depletion. Nevertheless, addition of salt to the growth media can reduce the risk of contamination and therefore halotolerant species might be suitable candidates for production in outdoor ponds.

High light showed an effect on TAG accumulation in the chlorophyte $D$. salina var. bardawil, as well as in the diatoms Phaeodactylum tricornutum and Thalassiosira pseudonana accumulating up to $39.5 \%$ of DW [37-39].

Another strategy for high TAG accumulation is the combination of stress factors, such as nitrogen depletion and high temperature $\left(33^{\circ} \mathrm{C}\right)$, which caused a 2-fold increase in Scenedesmus obtusus and $N$. salina $[40,41]$. A small dose of UV-C radiation under nitrogen depletion was able to double the TAG content in Tetraselmis sp. in only 2 days [42]. Conversely, the combination of high light $\left(300 \mu \mathrm{mol} \mathrm{m} \mathrm{m}^{-2} \mathrm{~s}^{-1}\right)$ and 
thermal stress $\left(30^{\circ} \mathrm{C}\right)$ was effective for the inducing TAG accumulation (up to $32 \%$ of DW) in the haptophyte Isochrysis galbana [38].

\subsection{LC-PUFA induction}

In most microalgal species, LC-PUFAs are mainly found in membrane lipids such as phospholipids and glycolipids, as these are important structural and functional components of the cell membranes, acting also in cellular signaling and playing an important role in the physiology of the microalgal cell [7]. Furthermore, EPA and DHA are considered to be important to maintain optimal membrane fluidity upon temperature, salinity or light intensity shifts. Additionally, LCPUFAs, especially those of the $\omega-3$ series, can act as antioxidants, protecting microalgal cells from oxidative damage caused by ROS $[43,44]$.

Large amounts of LC-PUFAs can be found in Stramenopiles and Haptista microalgae, probably due to the presence of an $\omega-3$ desaturase able to convert arachidonic acid (AA) to EPA or specific $\Delta 5$ elongase and $\Delta 4$ desaturase activities for the synthesis of DHA from EPA (Fig. 2). The synthesis of EPA and DHA is elevated under conditions promoting growth such as nitrogen and phosphorus repletion, most probably due to elevated synthesis of membranes in actively growing cells (Fig. 3). Under nitrogen repletion, the highest EPA contents of total fatty acids (TFA) were observed in N. oceanica (32\% of TFA) and Pavlova lutheri ( $29 \%$ of TFA), whereas P. tricornutum ( $30 \%$ of TFA) and I. galbana $(14 \%$ of TFA) displayed the highest DHA contents $[26,45,46]$. Furthermore, low light conditions are often reported as a factor for increasing LCPUFA contents, which might be due to an increase in thylakoid membranes to counterbalance the lower light availability $[47,48]$. EPA, a major chloroplast fatty acid in the eustigmatophyte Nannochloropsis sp., increased up to $38 \%$ of TFA when exposed to low light intensity $\left(50-60 \mu \mathrm{mol} \mathrm{m}^{-2} \mathrm{~s}^{-1}\right) \quad[29,49,50]$. Conversely, the DHA content increased from $12.6 \%$ to $19.2 \%$ and $8 \%$ to $14 \%$ of TFA in $P$. lutheri and I. galbana, respectively, under high light $\left(460 \mu \mathrm{mol} \mathrm{m}^{-2} \mathrm{~s}^{-1}\right)$ [51,52]. Higher levels of this LC-PUFA might be advantageous to microalgal cells due to their antioxidant properties, thus preventing the photooxidation of key components of the photosynthetic apparatus $[52,53]$.

Another important inducer of LC-PUFAs is temperature. Thermal shifts cause alterations in the fluidity of the cytoplasmic and thylakoid membranes, which in turn can be regulated through their fatty acid composition. Low temperatures increase lipid order in membranes, whereas high temperatures cause the opposite effect, enhancing the fluidization of membranes. Membrane fluidity is important for the function of light harvesting complexes, photosystems and membrane proteins such as translocators, sensor proteins and ion channels [54]. Therefore, under low temperature, usually more PUFAs are synthesized and incorporated into the membrane to maintain its correct fluidity. Decreasing temperatures $\left(13-17^{\circ} \mathrm{C}\right)$ increase $2-3$ times the EPA and DHA contents in several mesophilic species $[50,55,56]$. The application of both low light $\left(30 \mu \mathrm{mol} \mathrm{m}{ }^{-2} \mathrm{~s}^{-1}\right)$ and low temperature $\left(10{ }^{\circ} \mathrm{C}\right)$ even led to a 4-fold increase of EPA content ( $28 \%$ of TFA) in phospholipids in Nannochloropsis sp. [49].

Furthermore, salinity might also alter the fatty acid composition of microalgae. Under high salinity, there is usually a trend towards a higher saturation of the fatty acids. The adjustment of membrane permeability needed to avoid an extensive influx of $\mathrm{Na}^{+}$and $\mathrm{Cl}^{-}$ions might explain this response. The opposite trend is seen at low salinities, which seem to promote higher unsaturation levels in fatty acids. In Nannochloropsis sp. and I. galbana, low salinity of $10 \mathrm{ppt}$ led to increased contents of EPA and DHA, respectively [57-59].

Within the Archaeplastida lineage, the chlorophytes Parietochloris incisa and Tetraselmis sp. have been reported to accumulate significant amounts of LC-PUFAs. Under nitrogen depletion, EPA increased marginally in Tetraselmis sp. (10\% of TFA), which might be further triggered by exposure to UV-C radiation $[42,60]$. $P$. incisa is known for its high amounts of AA, which can reach $60 \%$ of TFA under low light $\left(30 \mu \mathrm{mol} \mathrm{m}^{-2} \mathrm{~s}^{-1}\right)$ and nitrogen depletion [61].

\subsection{Carotenoid induction}

In photoautotrophic organisms, carotenoids are essential accessory pigments in the photosystems and light harvesting complexes, playing an important role in energy transfer during photosynthesis [6]. Furthermore, under stress conditions, such as excess light, heat stress and nutrient depletion, the accumulation of ROS like singlet oxygen and free radicals can be quenched and scavenged by carotenoids, respectively. Because of this protective role, a few carotenoids (e.g. lutein and $\beta$-carotene) are essential components of the photosynthetic machinery, being present in the thylakoid, plastidial, ER, and mitochondrial membranes. However, there are other carotenoids (e.g. astaxanthin and canthaxanthin) that are only synthesized when specific environmental cues stimulate their accumulation.

The best induction technique for carotenoids in chlorophytes is high light under nutrient depletion resulting in increases of up to 60 -fold due to very low initial carotenoid contents (Fig. 3). H. pluvialis displayed the highest astaxanthin content $\left(30 \mathrm{mg} \mathrm{g}^{-1} \mathrm{DW}\right)$ upon exposure to a light intensity of $540 \mu \mathrm{mol} \mathrm{m}{ }^{-2} \mathrm{~s}^{-1}$ under nitrogen depletion [62]. Under similar conditions, in C. zofingiensis, astaxanthin accumulated as high as $4.9 \mathrm{mg} \mathrm{g}^{-1} \mathrm{DW}$, which is more than double the concentration (2.4 $\left.\mathrm{mg} \mathrm{g}^{-1} \mathrm{DW}\right)$ obtained upon nitrogen depletion [24,28]. Another producer of astaxanthin is $N$. oleoabundans with a content of $6.9 \mathrm{mg} \mathrm{g}^{-1}$ DW under nitrogen starvation [63]. The concomitant exposure to high light might improve, however, these values in the future. Concerning $\beta$ carotene, the highest production was observed in D. salina $\left(70 \mathrm{mg} \mathrm{g}^{-1}\right.$ DW) under high light $\left(1000 \mu \mathrm{mol} \mathrm{m}{ }^{-2} \mathrm{~s}^{-1}\right)$ and nitrogen depletion [64]. Nevertheless, in this species, high light and salt stress can only induce carotenoid accumulation when nutrients are limiting. Under these conditions, the levels of PSY and PDS transcripts encoding the enzymes responsible for the initial steps in carotenogenesis (Fig. 2) have been found to be upregulated [65]. However, in C. vulgaris and $P$. incisa, high light has been applied to enhance $\beta$-carotene contents 3 and 2-fold, respectively $[66,67]$.

Another important carotenoid in Archaeplastida is the xanthophyll lutein, a structural component of the light harvesting complex, occurring thus in the thylakoid membranes rather than in lipid droplets. The multiple functions of this orange pigment range from light harvesting to protection of the microalgal cell from excess light [11]. Thus, high lutein concentrations can be found under conditions promoting photosynthetic efficiency and cell growth. Lutein-rich species under nitrogen repletion are Muriellopsis sp., N. oleoabundans and Chlorella sorokiniana with contents of up to $20 \mathrm{mg} \mathrm{g}^{-1} \mathrm{DW}[63,68]$. However, heat stress $\left(33^{\circ} \mathrm{C}\right)$ led to enhanced accumulation of lutein in Muriellopsis sp. and Scenedesmus almeriensis $[68,69]$. Light intensity and quality are also important factors for lutein accumulation. The highest induction was observed in Tetraselmis suecica under short exposure to UV-C-radiation resulting in a 4-fold increase ( $\left.5 \mathrm{mg} \mathrm{g}^{-1} \mathrm{DW}\right)$ [70]. In C. zofingiensis, the lutein content doubled under a relatively low light intensity of $90 \mu \mathrm{mol}$ $\mathrm{m}^{-2} \mathrm{~s}^{-1}$ [71]. This enhanced lutein content under low light conditions could be due to a larger chloroplast and a concomitant increase in the number of thylakoids and associated pigment molecules, resulting in a more efficient light absorption and utilization [48]. Nevertheless, in $S$. almeriensis, high light $\left(1700 \mu \mathrm{mol} \mathrm{m}{ }^{-2} \mathrm{~s}^{-1}\right)$ increased the levels of lutein, which could be further enhanced (up to $0.54 \%$ of DW) by heat stress $\left(44^{\circ} \mathrm{C}\right)$ [69].

In Stramenopiles and Haptista microalgae, the highest increase in the carotenoids vaucheriaxanthin and $\beta$-carotene $(\approx 4$-fold $)$ was reported in $N$. gaditana upon exposure to high light $\left(1600 \mu \mathrm{mol} \mathrm{m}^{-2} \mathrm{~s}^{-1}\right)$ [72]. Under nitrogen depletion, $N$. gaditana and N. oceanica showed a 3fold increase of vaucheriaxanthin, canthaxanthin and zeaxanthin $[25,73]$, whereas the levels of fucoxanthin in the haptophyte I. galbana and in the diatom $P$. tricornutum under nitrogen repletion and low light 
$\left(13.5 \mu \mathrm{mol} \mathrm{m}^{-2} \mathrm{~s}^{-1}\right)$ increased from 0.06 to 0.15 and 0.08 to $0.2 \mathrm{mg}$ $\mathrm{g}^{-1}$ DW, respectively [74]. However, further research on microalgae of these evolutional lines is needed to find carotenoid producers and the best induction techniques.

\section{Induction of TAGs and/or carotenoids and LC-PUFAs}

\subsection{Induction of both TAGs and LC-PUFAs}

In most microalgae, under stress conditions such as nutrient depletion or in stationary phase, accumulated TAGs are mainly composed of saturated and monounsaturated fatty acids. Under these conditions, usually a decline of LC-PUFAs can be observed. Nevertheless, in N. oculata, P. lutheri, P. tricornutum, T. pseudonana and $P$. incisa, LC-PUFAs have been found to increase under TAGinductive conditions $[14,45,75,76]$. In $P$. incisa, under nitrogen starvation, the biosynthesis of AA was elevated due to transcriptional upregulation of the genes encoding $\Delta 12, \Delta 5$ and $\Delta 6$ desaturases, followed by accumulation of this fatty acid in TAGs rather than in phospho- or glycolipids $[77,78]$. LC-PUFAs deposited in TAGs could be used for an expedite adjustment of the composition of the cell membranes in response to a fast changing environment, avoiding a slower cycle of re-synthesis, assembly and deployment [79]. Alternatively, the observed increase in phospholipid/diacylglycerol acyltransferase (PDAT) and/or phospholipases in $P$. tricornutum suggests that LCPUFAs (e.g. EPA) can be remodeled from membrane lipids into TAGs [80]. This inverse flow, however, needs to be further investigated. Interestingly, species reported for being able to partition LC-PUFAs into TAGs seem also to contain high amounts of EPA, DHA or AA, but this apparent trend needs to be further researched to ascertain whether this holds true for a larger spectrum of microalgal species and whether upon long-term stressful conditions ( $>14$ days) these LC-PUFAs are diverted to TAGs as described previously [45].

\subsection{Induction of both TAGs and carotenoids}

In some species, TAGs and carotenoids accumulate under the same stress conditions, namely nitrogen depletion, alone or in combination with high light. A possible explanation for this could be that lipophilic carotenoids need TAG-rich lipid droplets in order to accumulate [81]. Moreover, it has been suggested that both TAG accumulation and carotenogenesis are interdependent. In $D$. salina, a correlated increase in oleic acid, one of the most abundant fatty acids in TAGs/lipid droplets, and $\beta$-carotene has been reported, a likely consequence of their co-accumulation in stromal lipid globules [39]. Conversely, astaxanthin accumulation in freshwater $H$. pluvialis and $C$. zofingiensis was found to take place in cytosolic lipid droplets, probably due to the export of this xanthophyll from the plastid to the cytoplasm. These extrathylakoidal carotenoids could protect the chloroplast from photooxidation under unfavorable conditions such as excess light [82,83]. This suggests that in other species, such as $N$. gaditana or $N$. oleoabundans, the accumulated carotenoid esters under stress conditions might be deposited in lipid droplets as well $[25,73]$.

\subsection{Induction of both LC-PUFAs and carotenoids}

In studies of Stramenopiles/Haptista microalgae carotenoids and LC-PUFAs have been found to be elevated under conditions promoting growth or low light. These conditions promote membrane adjustments and an increase in antenna size as described above. The LC-PUFAs are incorporated into polar lipids of non-photosynthetic and thylakoid membranes. Carotenoids under these conditions have an important function in the light harvesting process. Therefore, in species such as $N$. oceanica, P. tricornutum and I. galbana, high amounts of EPA and DHA accumulate together with $\beta$-carotene, violaxanthin and fucoxanthin $[26,29,46,74,84]$.

\section{Strategies to improve TAG, LC-PUFA and carotenoid production}

\subsection{Triple-producers}

From what has been said above, one of the key goals of current efforts in the field of microalgal biotechnology is to find tripleproducers, i.e. microalgal species or strains able to accumulate TAGs, LC-PUFAs and carotenoids simultaneously. A general trend seen in the literature is that, when compounds of two of the three classes of biochemicals increase, compounds of the third class often decrease. For example, LC-PUFAs usually do not accumulate when TAGs and carotenoids accumulate, although LC-PUFAs accumulate together with carotenoids under decreasing amounts of TAGs. A possible solution to this problem and an important feature of a triple-producer would be the incorporation of LC-PUFAs in TAGs as found in species discussed previously (see section 4.1). A second feature of such a microalga would be the accumulation of carotenoids in lipid bodies. In this manner, one stress factor like nitrogen depletion could induce the accumulation of high amounts of edible oils containing LC-PUFA-rich TAGs and carotenoids.

From the data gathered in the sections above, the most likely species to be a possible triple-producer without genetic modification is $P$. incisa (Table 1). In this species, the accumulation of TAGs containing AA could be accompanied by high $\beta$-carotene and/or lutein contents under stress conditions $[61,75,77]$. Nevertheless, so far, no study has reported on the best conditions for the co-accumulation of all three biotechnologically relevant classes of compounds and respective contents.

Alternative candidates as triple-producers are microalgae belonging to the genus Nannochloropsis (Fig. 4). These microalgae are known for their high EPA contents up to $38 \%$ of TFA under nutrient sufficient growth conditions $[49,73]$ and have been shown to divert EPA into TAGs upon exposure to long-term starvation [45]. The main carotenoid of this genus is vaucheriaxanthin, whose contents increase also under TAG-inductive conditions. The low market value of this carotenoid might hinder further research, though. Alternatively, zeaxanthin produced by this species is more promising in terms of market value and applications as antioxidant and food colorant [3]. Thus, the concurrent production of LC-PUFAs in TAGs and carotenoids in these species is a high possibility that should be further investigated in order to improve the content of both classes of high-value compounds using a common trigger.

Other species of interest are the haptophytes I. galbana and P. lutheri as well as the diatoms $P$. tricornutum and T. pseudonana due to their high contents of EPA and DHA that are partitioned into TAGs under nitrogen depletion (Fig. 4). These microalgae belonging to the Stramenopiles and Haptista evolutionary lines contain significant amounts of fucoxanthin [17]. However, this biomedically important xanthophyll decreases upon exposure of these microalgae to stress conditions. These microalgae can be improved, however, in the near future, by screening for mutants able to accumulate fucoxanthin together with LC-PUFA-rich TAGs under same growth conditions.

Eventually, the species C. zofingiensis and $N$. oleoabundans show potential as triple-producers due to the accumulation of high amounts of TAGs and astaxanthin. Nevertheless, the lack of significant amounts of LC-PUFAs hampers their use as a triple-producer. However, this drawback might be addressed by metabolic engineering or mutant selection via high-throughput methods.

\subsection{Metabolic engineering}

Metabolic engineering is one important tool for the improvement of 
Table 1

Possible target species for improvement towards simultaneous production of LC-PUFAs in triacylglycerols (TAGs) and carotenoids and their productions found in literature.

\begin{tabular}{|c|c|c|c|c|c|c|c|c|c|c|c|}
\hline \multirow[t]{2}{*}{ Species } & \multirow[t]{2}{*}{ Inducer } & \multirow[t]{2}{*}{ TAGs $[\%$ DW] } & \multicolumn{5}{|c|}{ Carotenoids $\left[\mathrm{mg} \mathrm{g}^{-1} \mathrm{DW}\right]$} & \multicolumn{3}{|c|}{ LC-PUFAs [\% TFA] } & \multirow[t]{2}{*}{ Ref. } \\
\hline & & & Ast & $\beta$-car & Lut & Vau & Fuc & AA $(20: 4)$ & EPA (20:5) & DHA (22:6) & \\
\hline \multicolumn{12}{|l|}{ Archaeplastida } \\
\hline C. zofingiensis & $\mathrm{ND}+\mathrm{HL}$ & $12-40$ & $4.9-6.3$ & & & & & & & & {$[28,85,86]$} \\
\hline \multirow[t]{2}{*}{ N. oleoabundans } & $\mathrm{ND}$ & $12-42$ & 6.9 & & & & & & & & {$[23,63,87,88]$} \\
\hline & NR & & & & 19.4 & & & & & & [63] \\
\hline \multirow[t]{2}{*}{ P. incisa } & ND & 32 & & & & & & $47-60$ & & & {$[61,67,75]$} \\
\hline & HL & & & $9.3^{\mathrm{b}}$ & $11.6^{\mathrm{b}}$ & & & & & & [67] \\
\hline \multicolumn{12}{|l|}{ Haptista } \\
\hline \multirow[t]{2}{*}{ I. galbana } & $\mathrm{HL}+\mathrm{HT}$ & 32 & & & & & & & & & [38] \\
\hline & LL & & & & & & 0.15 & & & 17 & {$[46,74]$} \\
\hline P. lutheri & ND & $75^{a}$ & & & & & & & 11 & 9 & {$[14,45]$} \\
\hline \multicolumn{12}{|l|}{ Stramenopiles } \\
\hline \multirow[t]{3}{*}{ N. gaditana } & ND & 38 & & & & & & & & & {$[25,89]$} \\
\hline & HL & & & $1.8^{\mathrm{c}}$ & & $1.5^{\mathrm{c}}$ & & & & & [72] \\
\hline & LL & & & & & & & & 38 & & [89] \\
\hline \multirow[t]{2}{*}{ N. oculata } & $\mathrm{ND}+\mathrm{HL}$ & $40-43$ & & & & & & & $170^{\mathrm{d}}$ & & {$[29,45,90]$} \\
\hline & NR/LL & & & & & & & & $20-35$ & & {$[29,91]$} \\
\hline \multirow[t]{2}{*}{ N. oceanica } & ND & 35 & & & & & & & & & [26] \\
\hline & NR/LS & & & 0.4 & & & & & $16-32$ & & {$[26,73]$} \\
\hline \multirow[t]{2}{*}{ P. tricornutum } & ND/HL & $23-40$ & & & & & & & $150^{\mathrm{d}}$ & & {$[23,38,45]$} \\
\hline & $\mathrm{NR}+\mathrm{LL}$ & & & & & & 5.5 & & $20-30$ & 3 & {$[74,84]$} \\
\hline \multirow[t]{2}{*}{ T. pseudonana } & $\mathrm{ND}$ & 14 & & & & & & & $375^{d}$ & $40^{\mathrm{d}}$ & {$[37,45]$} \\
\hline & NR & & & & & & & & $16-32$ & & {$[37,45]$} \\
\hline
\end{tabular}

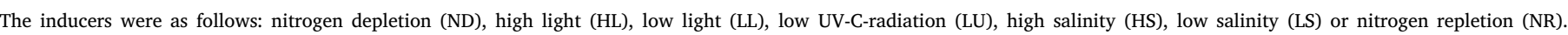

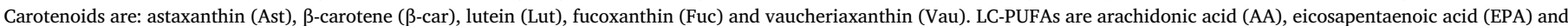

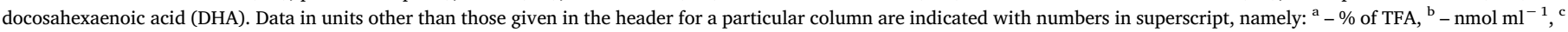
$-\mathrm{mg} \mathrm{L}^{-1} \mathrm{day}^{-1} \mathrm{~d}^{\mathrm{d}}-\mathrm{fg}_{\mathrm{g}}$ cell ${ }^{-1}$. More detailed information can be found in Table S1.

specific biosynthesis pathways, which can also be employed to improve our knowledge of microalgal metabolic and cellular processes. Several authors have proposed that genetic engineering is the key to enhancing productivity of TAGs (reviewed by [92-94]) or carotenoids and modifying the PUFA profile towards those fatty acids that better conform to the need of target industrial or nutritional applications [95]. Among the metabolic engineering strategies to boost TAGs, efforts to overexpress enzymes involved in the biosynthesis of fatty acids [96] to manipulate TAG assembly [97-99] or to enhance the supply of carbon precursors or NADPH needed for the synthesis of TAGs

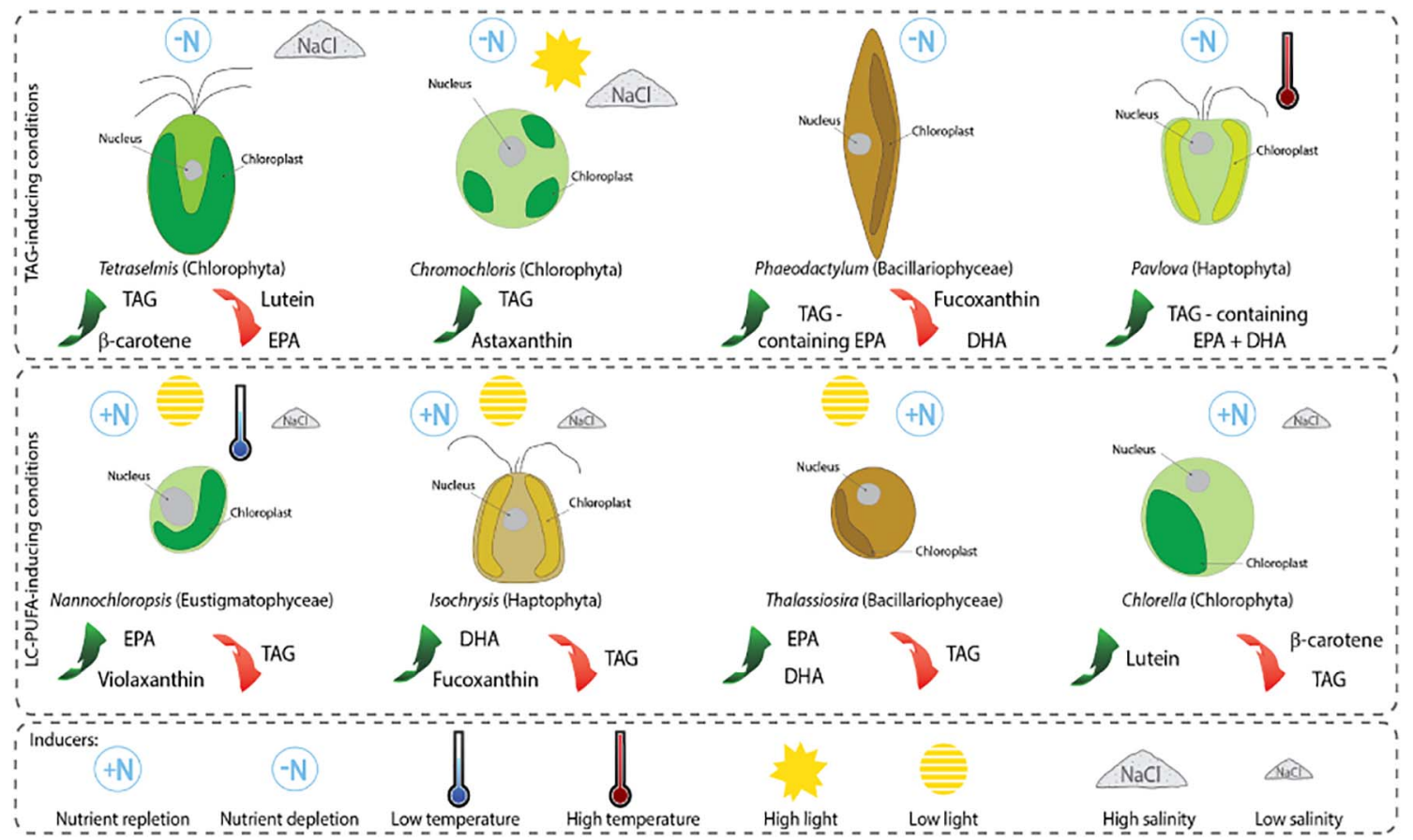

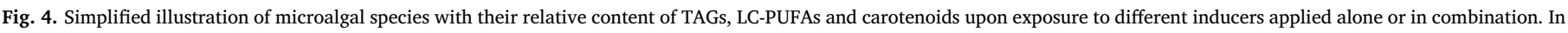

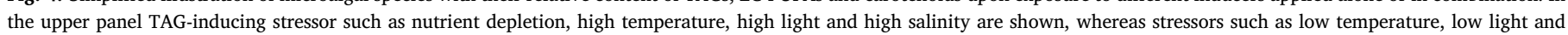
nutrient replete conditions usually lead to elevated LC-PUFA contents as represented in the lower panel. 
$[100,101]$ have been reported. Other strategies involve the inhibition of competitive pathways such as starch biosynthesis or $\beta$-oxidation of lipids. For example, in $N$. oceanica under nitrogen starvation the LCPUFA biosynthesis is inhibited by transcriptional downregulation of $\Delta 12$ desaturase catalyzing the conversion of oleic acid into linoleic acid, a precursor of LC-PUFAs [25]. Interestingly, this limitation can be overcome by overexpressing the endogenous enzyme, leading to increased accumulation of LC-PUFAs in TAGs under nitrogen starvation [102]. In P. tricornutum the overexpression of DGAT led to increased oil droplets with a simultaneous increase in EPA in TAGs [103]. The same strategy also was used in $C$. reinhardtii with different results depending on the DGAT isoenzyme chosen $[104,105]$. The partitioning of EPA, but not of DHA, into TAGs in P. tricornutum has already been shown by Tonon et al. [45]. Nevertheless, a different study in P. tricornutum used metabolic engineering of several desaturases and elongases leading to increased DHA synthesis with an ensuing accumulation in TAGs [106]. A few attempts at engineering the biosynthesis of carotenoids have targeted the PSY and PDS genes encoding phytoene synthase and desaturase, respectively. These enzymes catalyze the first two steps of the carotenoid biosynthetic pathway, thus diverting isoprenoid compounds into this pathway (Fig. 2). The successful expression of exogenous PSY in the model organism $C$. reinhardtii led to an increase in lutein [107]. Furthermore, keto-carotenoids such as astaxanthin that are not present in the wild-type of $C$. reinhardtii or $D$. salina can be synthesized by the expression of the $B K T$ gene encoding $\beta$-carotene ketolase $[108,109]$. Nevertheless, the engineering of metabolic pathways is often challenging and overproduction of the desired compound is difficult to achieve. One reason for this is that the targeted gene may not be responsible for the bottleneck of the pathway, as one pathway can include several rate-limiting steps, and thus several enzymes need to be overexpressed. Very recently, a novel approach called "transcriptional engineering" has been put forward. Instead of targeting genes encoding metabolic enzymes, the overexpression of transcription factors or regulatory elements might be a possible methodology to enhance multiple components of one or several metabolic pathways [110]. One starting point could be the transcriptional engineering of the LC-PUFA synthesis as genes of desaturases are expressed according to a similar pattern and could be co-transcribed as an operon [111].

\subsection{Fluorescent activated cell sorting as a powerful tool for strain improvement}

Although metabolic engineering shows great promise, it is often restricted by the limited knowledge of the biosynthesis and storage of TAGs, carotenoid and LC-PUFAs and by current regulatory restrictions on genetically modified organisms (GMOs). To overcome this issue, fluorescent activated cell sorting (FACS) can be used to isolate hyper- or hypoproducing mutant strains [112]. For this approach, the aforementioned target species are interesting candidates due to the accumulation of high amounts of carotenoids and the partitioning of LC-PUFAs into TAGs. However, for this rapid selection, algal cells need to be stained with a fluorescent dye for the desired compound. The isolation of lipidrich strains has been achieved for T. suecica, Chlorella sp. and Nannochloropsis sp. by either Nile-red or the non-toxic BODIPY 505/515 staining procedure coupled with repeated rounds of FACS [113-115]. The lipid-rich microalgae can either derive from spontaneous mutations or from random mutagenesis using ethyl methane sulfonate or exposure to high doses of UV radiation. Furthermore, repeated rounds of mutant selection ensure the stability of genetic mutations (Fig. 5). Carotenoid hyperproducing strains of $D$. salina have been isolated by the same method. As carotenoid and neutral lipid accumulation seem to be connected, Nile-red can be used as indirect marker of carotenoids [116]. However, to the best of our knowledge, there have not been any successful attempts at isolating LC-PUFA-rich microalgae by FACS due to the inability of current fluorochromes to specifically stain polyunsaturated fatty acids. However, it has been reported an increase of LC-
PUFAs in high lipid content strains mutagenized by UV radiation [113]. As a matter of fact, the generation and the selection of stable mutants by FACS coupled with the elucidation of changes at the level of the genome and transcriptome could generate interesting data concerning what regulatory components (e.g. key enzymes, transcription factors or signal-transducing pathways) are responsible for enhanced carotenoid and lipid biosynthesis in hyperproducing mutants. Finding these molecular switches responsible for such traits could provide further knowledge of how microalgal cells sense the environment and how they respond to it in terms of accumulation and compartmentalization of TAGs, carotenoids and LC-PUFAs, especially under nitrogen starvation. A particular issue worth investigating, and related to this applied objective, is to learn how microalgae remodel their membranes as part of the response to growth-enhancing conditions and/or environmental stress.

\section{Conclusion}

Microalgae are rich sources of multiple bioactive compounds such as LC-PUFAs, TAGs and carotenoids with applications in food, feed and fuel markets. Recent trends in microalgal biotechnology point to the simultaneous accumulation of these high-valuable compounds and lipids by one microalgal species to turn the production into an economically feasible venture. Analysis of the current state of the art revealed that the chlorophyte $P$. incisa is a potential triple-producer, being able to accumulate the three lipophilic classes of compounds that are amenable to be used in different streams in a biorefinery. Furthermore, oleaginous species of the Stramenopiles lineage such as $N$. oculata or $P$. tricornutum show the ability of a similar production process. However, concomitant carotenoid accumulation is yet to be achieved. Oleaginous chlorophytes usually display large accumulation of carotenoids under stress conditions, but only marginal EPA and DHA contents. Most probably, the best strategy to obtain triple-producers will be to look for carotenoid-rich strains containing TAGs composed of LC-PUFAs. Metabolic engineering of the LC-PUFA biosynthesis in microalgae of Stramenopiles has already proven that under specific genetic backgrounds microalgae synthesize high amounts of LC-PUFAs and incorporated these into TAGs under nitrogen depletion. Instead of the generation of genetically modified microalgae, naturally occurring lipid-, LC-PUFA- or carotenoid-hyperproducing mutants can be obtained by FACS-based selection (Fig. 5). Even though both methods have been successfully applied to microalgae for one or the other compound, the genetic analysis of the derived mutants is lacking, which could lead to the detection of genes or transcription factors responsible for the higher accumulation of valuable compounds. Thus, further knowledge about the metabolic pathways and especially the mechanism for the partitioning of LC-PUFAs into TAGs can be acquired, leading to a better understanding of the response of the microalgal metabolism to different stress factors. The species and techniques suggested in this review will hopefully guide the research into the direction of the production of multiple valuable compounds by microalgae, making them a promising sustainable resource of food, feed and energy.

\section{Contributions}

The conception and design of the current review were carried out by all authors. Data acquisition and analysis were primarily performed by Lisa Schüler (LS). Peter Schulze (PS) and Hugo Pereira (HP) played important roles in data processing and display. LS and João Varela (JV) performed the initial drafting of the article, and subsequent versions were drafted and reviewed by PS (microalgal biotechnology and physiology), HP (biology, screening methodologies and bioproducts), Luísa Barreira (bioproducts) and Rosa Léon (metabolic engineering). All authors contributed to the final approval of the article. 


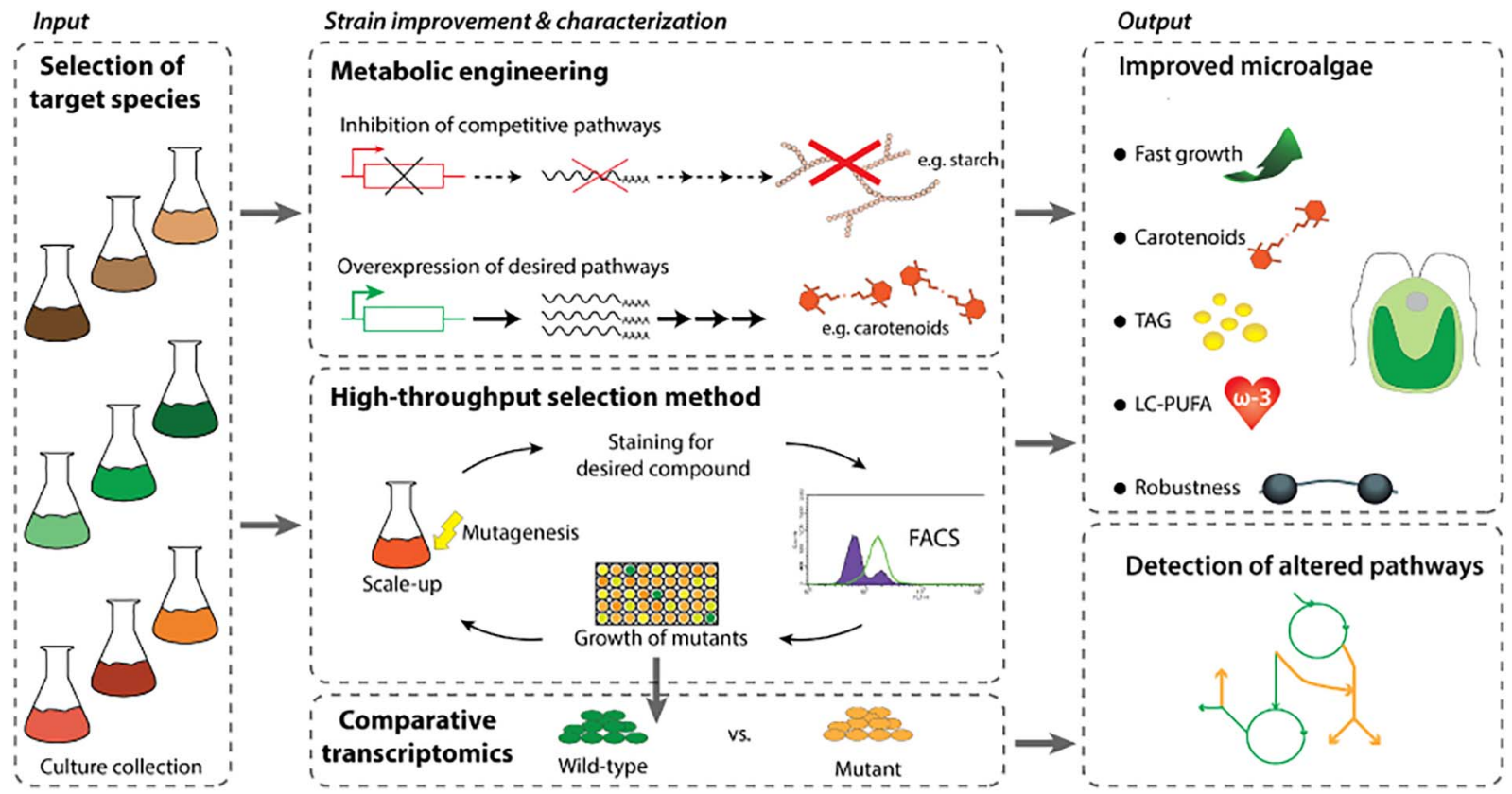

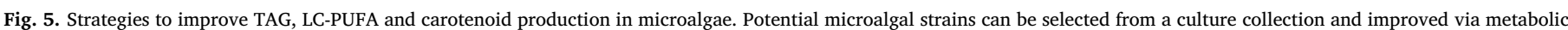

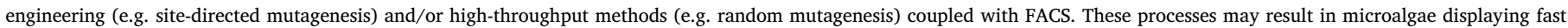

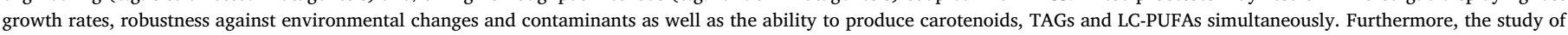

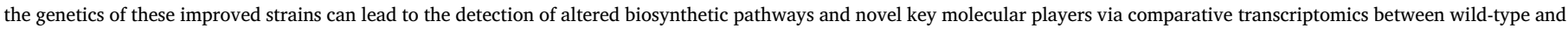
mutant.

\section{Acknowledgements}

The authors are indebted to the Foundation for Science and Technology (Portugal) for funding through CCMAR/Multi/04326/ 2013 research programme and doctoral research grants (SFRH/BD/ 105541/2014; SFRH/BD/115325/2016) awarded to HP and LS. RL gratefully acknowledges the financial support from the Spanish Ministry of Economy and Competitiveness (AGL2016-74866-C3-02) and CEIMAR. PS acknowledges the funding support received from Nord University and Nordland County Government project Bioteknologi- en framtidsrettet næring.

\section{Appendix A. Supplementary data}

Supplementary data to this article can be found online at http://dx. doi.org/10.1016/j.algal.2017.05.025.

\section{References}

[1] P.J.L.B. Williams, L.M.L. Laurens, Microalgae as biodiesel \& biomass feedstocks: review \& analysis of the biochemistry, energetics \& economics, Energy Environ. Sci. 3 (2010) 554, http://dx.doi.org/10.1039/b924978h.

[2] F. Burki, M. Kaplan, D.V. Tikhonenkov, V. Zlatogursky, B.Q. Minh, L.V. Radaykina, et al., Untangling the early diversification of eukaryotes: a phylogenomic study of the evolutionary origins of Centrohelida, Haptophyta and Cryptista, Proc. R. Soc. B Biol. Sci. 283 (2016) 20152802, http://dx.doi.org/10. 1098/rspb.2015.2802.

[3] M.A. Borowitzka, High-value products from microalgae-their development and commercialisation, J. Appl. Phycol. 25 (2013) 743-756, http://dx.doi.org/10. 1007/s10811-013-9983-9.

[4] Y. Li-Beisson, F. Beisson, W. Riekhof, Metabolism of acyl-lipids in Chlamydomonas reinhardtii, Plant J. 82 (2015) 504-522, http://dx.doi.org/10.1111/tpj.12787.

[5] P.T. Pienkos, A. Darzins, The promise and challenges of microalgal-derived biofuels, biofuels, Bioprod. Biorefining. 3 (2009) 431-440, http://dx.doi.org/10. 1002/bbb.159.

[6] J.C. Varela, H. Pereira, M. Vila, R. León, Production of carotenoids by microalgae: achievements and challenges, Photosynth. Res. 125 (2015) 423-436, http://dx. doi.org/10.1007/s11120-015-0149-2.

[7] D. Martins, L. Custódio, L. Barreira, H. Pereira, R. Ben-Hamadou, J. Varela, et al., Alternative sources of $n$-3 long-chain polyunsaturated fatty acids in marine microalgae, Mar. Drugs. 11 (2013) 2259-2281, http://dx.doi.org/10.3390/ md11072259.

[8] I. Khozin-Goldberg, U. Iskandarov, Z. Cohen, LC-PUFA from photosynthetic microalgae: occurrence, biosynthesis, and prospects in biotechnology, Appl.
Microbiol. Biotechnol. 91 (2011) 905-915, http://dx.doi.org/10.1007/s00253011-3441-x.

[9] A.J. Klok, P.P. Lamers, D.E. Martens, R.B. Draaisma, R.H. Wijffels, Edible oils from microalgae: insights in TAG accumulation, Trends Biotechnol. 32 (2014) 521-528, http://dx.doi.org/10.1016/j.tibtech.2014.07.004.

[10] A. Minhas, P. Hodgson, C. Barrow, A. Adholeya, A review on the assessment of stress conditions for simultaneous production of microalgal lipids and carotenoids, Front. Microbiol. 7 (2016) 1-19, http://dx.doi.org/10.3389/fmicb.2016.00546.

[11] K.J.M. Mulders, P.P. Lamers, D.E. Martens, R.H. Wijffels, Phototrophic pigment production with microalgae: biological constraints and opportunities, J. Phycol. 50 (2014) 229-242, http://dx.doi.org/10.1111/jpy.12173.

[12] I. Khozin-Goldberg, Z. Cohen, Unraveling algal lipid metabolism: recent advances in gene identification, Biochimie 93 (2011) 91-100, http://dx.doi.org/10.1016/j biochi.2010.07.020.

[13] R.J. Henderson, E.E. Mackinlay, P. Hodgson, J.L. Harwood, Differential effects of the substituted pyridazinone herbicide sandoz 9785 on lipid composition and biosynthesis in photosynthetic and non-photosynthetic marine microalgae, J. Exp. Bot. 41 (1990) 729-736, http://dx.doi.org/10.1093/jxb/41.6.729.

[14] F. Guihéneuf, D. Stengel, LC-PUFA-enriched oil production by microalgae: accumulation of lipid and triacylglycerols containing n-3 LC-PUFA is triggered by nitrogen limitation and inorganic carbon availability in the marine haptophyte Pavlova lutheri, Mar. Drugs. 11 (2013) 4246-4266, http://dx.doi.org/10.3390/ md11114246.

[15] M. Shumskaya, E.T. Wurtzel, The carotenoid biosynthetic pathway: thinking in all dimensions, Plant Sci. 208 (2013) 58-63, http://dx.doi.org/10.1016/j.plantsci. 2013.03.012.

[16] L. Davidi, Y. Levin, S. Ben-Dor, U. Pick, Proteome analysis of cytoplasmatic and plastidic $\beta$-carotene lipid droplets in Dunaliella bardawil, Plant Physiol. 167 (2015) 60-79, http://dx.doi.org/10.1104/pp.114.248450.

[17] S. Takaichi, Carotenoids in algae: distributions, biosyntheses and functions, Mar. Drugs. 9 (2011) 1101-1118, http://dx.doi.org/10.3390/md9061101.

[18] M.J. Griffiths, S.T.L. Harrison, Lipid productivity as a key characteristic for choosing algal species for biodiesel production, J. Appl. Phycol. 21 (2009) 493-507, http://dx.doi.org/10.1007/s10811-008-9392-7.

[19] J. Fan, C. Andre, C. Xu, A chloroplast pathway for the de novo biosynthesis of triacylglycerol in Chlamydomonas reinhardtii, FEBS Lett. 585 (2011) 1985-1991, http://dx.doi.org/10.1016/j.febslet.2011.05.018.

[20] C. Goodson, R. Roth, Z.T. Wang, U. Goodenough, Structural correlates of cytoplasmic and chloroplast lipid body synthesis in Chlamydomonas reinhardtii and stimulation of lipid body production with acetate boost, Eukaryot. Cell 10 (2011) 1592-1606, http://dx.doi.org/10.1128/EC.05242-11.

[21] Q. Hu, M. Sommerfeld, E. Jarvis, M. Ghirardi, M. Posewitz, M. Seibert, et al., Microalgal triacylglycerols as feedstocks for biofuel production: perspectives and advances, Plant J. 54 (2008) 621-639, http://dx.doi.org/10.1111/j.1365-313X. 2008.03492.x.

[22] P.P. Lamers, M. Janssen, R.C.H. De Vos, R.J. Bino, R.H. Wijffels, Exploring and exploiting carotenoid accumulation in Dunaliella salina for cell-factory applications, Trends Biotechnol. 26 (2008) 631-638, http://dx.doi.org/10.1016/j. tibtech.2008.07.002.

[23] G. Breuer, P.P. Lamers, D.E. Martens, R.B. Draaisma, R.H. Wijffels, The impact of nitrogen starvation on the dynamics of triacylglycerol accumulation in nine 
microalgae strains, Bioresour. Technol. 124 (2012) 217-226, http://dx.doi.org/ 10.1016/j.biortech.2012.08.003

[24] K.J.M. Mulders, J.H. Janssen, D.E. Martens, R.H. Wijffels, P.P. Lamers, Effect of biomass concentration on secondary carotenoids and triacylglycerol (TAG) accumulation in nitrogen-depleted Chlorella zofingiensis, Algal Res. 6 (2014) 8-16, http://dx.doi.org/10.1016/j.algal.2014.08.006.

[25] D. Simionato, M.A. Block, N. La Rocca, J. Jouhet, E. Marechal, G. Finazzi, et al., The response of Nannochloropsis gaditana to nitrogen starvation includes de novo biosynthesis of triacylglycerols, a decrease of chloroplast galactolipids, and reorganization of the photosynthetic apparatus, Eukaryot. Cell 12 (2013) 665-676, http://dx.doi.org/10.1128/EC.00363-12.

[26] Y. Meng, J. Jiang, H. Wang, X. Cao, S. Xue, Q. Yang, et al., The characteristics of TAG and EPA accumulation in Nannochloropsis oceanica IMET1 under different nitrogen supply regimes, Bioresour. Technol. 179 (2015) 483-489, http://dx.doi. org/10.1016/j.biortech.2014.12.012.

[27] I.T.D. Cabanelas, D.M.M. Kleinegris, R.H. Wijffels, M.J. Barbosa, Repeated nitrogen starvation doesn't affect lipid productivity of Chlorococcum littorale, Bioresour. Technol. 219 (2016) 576-582, http://dx.doi.org/10.1016/j.biortech. 2016.08.009.

[28] J. Liu, X. Mao, W. Zhou, M.T. Guarnieri, Simultaneous production of triacylglycerol and high-value carotenoids by the astaxanthin-producing oleaginous green microalga Chlorella zofingiensis, Bioresour. Technol. 214 (2016) 319-327, http:// dx.doi.org/10.1016/j.biortech.2016.04.112.

[29] X. Ma, J. Liu, B. Liu, T. Chen, B. Yang, F. Chen, Physiological and biochemical changes reveal stress-associated photosynthetic carbon partitioning into triacylglycerol in the oleaginous marine alga Nannochloropsis oculata, Algal Res. 16 (2016) 28-35, http://dx.doi.org/10.1016/j.algal.2016.03.005.

[30] M.A. Chia, A.T. Lombardi, M. de G.G. Melão, C.C. Parrish, Lipid composition of Chlorella vulgaris (Trebouxiophyceae) as a function of different cadmium and phosphate concentrations, Aquat. Toxicol. 128-129 (2013) 171-182, http://dx. doi.org/10.1016/j.aquatox.2012.12.004.

[31] K. Liang, Q. Zhang, M. Gu, W. Cong, Effect of phosphorus on lipid accumulation in freshwater microalga Chlorella sp, J. Appl. Phycol. 25 (2013) 311-318, http://dx. doi.org/10.1007/s10811-012-9865-6.

[32] Y.-H. Wu, Y. Yu, H.-Y. Hu, Microalgal growth with intracellular phosphorus for achieving high biomass growth rate and high lipid/triacylglycerol content simultaneously, Bioresour. Technol. 192 (2015) 374-381, http://dx.doi.org/10. 1016/j.biortech.2015.05.057.

[33] I. Khozin-Goldberg, Z. Cohen, The effect of phosphate starvation on the lipid and fatty acid composition of the fresh water eustigmatophyte Monodus subterraneus, Phytochemistry 67 (2006) 696-701, http://dx.doi.org/10.1016/j.phytochem. 2006.01.010.

[34] I. Pancha, K. Chokshi, R. Maurya, K. Trivedi, S.K. Patidar, A. Ghosh, et al., Salinity induced oxidative stress enhanced biofuel production potential of microalgae Scenedesmus sp. CCNM 1077, Bioresour. Technol. 189 (2015) 341-348, http://dx. doi.org/10.1016/j.biortech.2015.04.017.

[35] M.L. Bartley, W.J. Boeing, A.A. Corcoran, F.O. Holguin, T. Schaub, Effects of salinity on growth and lipid accumulation of biofuel microalga Nannochloropsis salina and invading organisms, Biomass Bioenergy 54 (2013) 83-88, http://dx.doi. org/10.1016/j.biombioe.2013.03.026.

[36] M. Takagi, Karseno, T. Yoshida, Effect of salt concentration on intracellular accumulation of lipids and triacylglyceride in marine microalgae Dunaliella cells, J. Biosci. Bioeng. 101 (2006) 223-226, http://dx.doi.org/10.1263/jbb.101.223.

[37] M.R. Brown, G.A. Dunstan, S.J. Norwood, K.A. Miller, Effects of harvest stage and light on the biochemical composition of the diatom Thalassiosira pseudonana, J. Phycol. 32 (1996) 64-73, http://dx.doi.org/10.1111/j.0022-3646.1996.00064.x.

[38] D.P.K. Nogueira, A.F. Silva, O.Q.F. Araújo, R.M. Chaloub, Impact of temperature and light intensity on triacylglycerol accumulation in marine microalgae, Biomass Bioenergy 72 (2015) 280-287, http://dx.doi.org/10.1016/j.biombioe.2014.10. 017

[39] S. Rabbani, P. Beyer, J.v. Lintig, P. Hugueney, H. Kleinig, Induced $\beta$-carotene synthesis driven by triacylglycerol deposition in the unicellular alga Dunaliella bardawil, Plant Physiol. 116 (1998) 1239-1248, http://dx.doi.org/10.1104/pp. 116.4.1239.

[40] L. Xia, S. Song, C. Hu, High temperature enhances lipid accumulation in nitrogendeprived Scenedesmus obtusus XJ-15, J. Appl. Phycol. 28 (2016) 831-837, http:// dx.doi.org/10.1007/s10811-015-0636-z.

[41] E.M. Fakhry, D.M. El Maghraby, Lipid accumulation in response to nitrogen limitation and variation of temperature in Nannochloropsis salina, Bot. Stud. 56 (2015) 1-8, http://dx.doi.org/10.1186/s40529-015-0085-7.

[42] K. Sharma, Y. Li, P.M. Schenk, UV-C-mediated lipid induction and settling, a step change towards economical microalgal biodiesel production, Green Chem. 16 (2014) 3539-3548, http://dx.doi.org/10.1039/C4GC00552J.

[43] H. Okuyama, Y. Orikasa, T. Nishida, Significance of antioxidative functions of eicosapentaenoic and docosahexaenoic acids in marine microorganisms, Appl. Environ. Microbiol. 74 (2008) 570-574, http://dx.doi.org/10.1128/AEM. 02256-07.

[44] D. Richard, K. Kefi, U. Barbe, P. Bausero, F. Visioli, Polyunsaturated fatty acids as antioxidants, Pharmacol. Res. 57 (2008) 451-455, http://dx.doi.org/10.1016/j. phrs.2008.05.002.

[45] T. Tonon, D. Harvey, T.R. Larson, I.A. Graham, Long chain polyunsaturated fatty acid production and partitioning to triacylglycerols in four microalgae, Phytochemistry 61 (2002) 15-24, http://dx.doi.org/10.1016/S0031-9422(02) 00201-7.

[46] J. Liu, M. Sommerfeld, Q. Hu, Screening and characterization of Isochrysis strains and optimization of culture conditions for docosahexaenoic acid production, Appl. Microbiol. Biotechnol. 97 (2013) 4785-4798, http://dx.doi.org/10.1007/s00253013-4749-5.

[47] T. Fisher, T. Berner, D. Iluz, Z. Dubinsky, The kinetics of the photoacclimation response of Nannochloropsis sp. (Eustigmatophyceae): a study of changes in ultrastructure and PSU density, J. Phycol. 34 (1998) 818-824, http://dx.doi.org/ 10.1046/j.1529-8817.1998.340818x.

[48] T. Berner, Z. Dubinsky, K. Wyman, P.G. Falkowski, Photoadaptation and the "package" effect in Dunaliella tertiolecta (Chlorophyceae), J. Phycol. 25 (1989) 70-78, http://dx.doi.org/10.1111/j.0022-3646.1989.00070.x.

[49] M. Mitra, S.K. Patidar, S. Mishra, Integrated process of two stage cultivation of Nannochloropsis sp. for nutraceutically valuable eicosapentaenoic acid along with biodiesel, Bioresour. Technol. 193 (2015) 363-369, http://dx.doi.org/10.1016/j. biortech.2015.06.033.

[50] J. Van Wagenen, T.W. Miller, S. Hobbs, P. Hook, B. Crowe, M. Huesemann, Effects of light and temperature on fatty acid production in Nannochloropsis salina, Energies. 5 (2012) 731-740, http://dx.doi.org/10.3390/en5030731.

[51] F. Guihéneuf, V. Mimouni, L. Ulmann, G. Tremblin, Combined effects of irradiance level and carbon source on fatty acid and lipid class composition in the microalga Pavlova lutheri commonly used in mariculture, J. Exp. Mar. Bio. Ecol. 369 (2009) 136-143, http://dx.doi.org/10.1016/j.jembe.2008.11.009.

[52] I. Tzovenis, N. De Pauw, P. Sorgeloos, Effect of different light regimes on the docosahexaenoic acid (DHA) content of Isochrysis aff. galbana (clone T-ISO), Aquac. Int. 5 (1997) 489-507, http://dx.doi.org/10.1023/A:1018349131522.

[53] P.A. Thompson, P.J. Harrison, J.N.C. Whyte, Influence of irradiance on fatty acid composition of phytoplankton, J. Phycol. 26 (1990) 278-288, http://dx.doi.org/ 10.1111/j.0022-3646.1990.00278.x.

[54] D.A. Los, K.S. Mironov, S.I. Allakhverdiev, Regulatory role of membrane fluidity in gene expression and physiological functions, Photosynth. Res. 116 (2013) 489-509, http://dx.doi.org/10.1007/s11120-013-9823-4.

[55] H. Tatsuzawa, E. Takizawa, Changes in lipid and fatty acid composition of Pavlova lutheri, Phytochemistry 40 (1995) 397-400, http://dx.doi.org/10.1016/00319422(95)00327-4.

[56] H. Jiang, K. Gao, Effects of lowering temperature during culture on the production of polyunsaturated fatty acids in the marine diatome Phaeodactylum tricornutum (Bacillariophyceae), J. Phycol. 40 (2004) 651-654, http://dx.doi.org/10.1111/j. 1529-8817.2004.03112.x.

[57] S.M. Renaud, D.L. Parry, Microalgae for use in tropical aquaculture II: effect of salinity on growth, gross chemical composition and fatty acid composition of three species of marine microalgae, J. Appl. Phycol. 6 (1994) 347-356, http://dx.doi. org/10.1007/BF02181949.

[58] D. Pal, I. Khozin-Goldberg, S. Didi-Cohen, A. Solovchenko, A. Batushansky, Y. Kaye, et al., Growth, lipid production and metabolic adjustments in the euryhaline eustigmatophyte Nannochloropsis oceanica CCALA 804 in response to osmotic downshift, Appl. Microbiol. Biotechnol. 97 (2013) 8291-8306, http://dx. doi.org/10.1007/s00253-013-5092-6.

[59] N. Gu, Q. Lin, G. Li, Y. Tan, L. Huang, J. Lin, Effect of salinity on growth, biochemical composition, and lipid productivity of Nannochloropsis oculata CS 179, Eng. Life Sci. 12 (2012) 631-637, http://dx.doi.org/10.1002/elsc. 201100204.

[60] H.-P. Tsai, L.-T. Chuang, C.-N.N. Chen, Production of long chain omega-3 fatty acids and carotenoids in tropical areas by a new heat-tolerant microalga Tetraselmis sp. DS3, Food Chem. 192 (2016) 682-690, http://dx.doi.org/10.1016/ j.foodchem.2015.07.071.

[61] A.E. Solovchenko, I. Khozin-Goldberg, S. Didi-Cohen, Z. Cohen, M.N. Merzlyak, Effects of light intensity and nitrogen starvation on growth, total fatty acids and arachidonic acid in the green microalga Parietochloris incisa, J. Appl. Phycol. 20 (2008) 245-251, http://dx.doi.org/10.1007/s10811-007-9233-0.

[62] E. Imamoglu, M.C. Dalay, F.V. Sukan, Influences of different stress media and high light intensities on accumulation of astaxanthin in the green alga Haematococcus pluvialis, New Biotechnol. 26 (2009) 199-204, http://dx.doi.org/10.1016/j.nbt. 2009.08.007.

[63] I. Urreta, Z. Ikaran, I. Janices, E. Ibañez, M. Castro-Puyana, S. Castañón, et al., Revalorization of Neochloris oleoabundans biomass as source of biodiesel by concurrent production of lipids and carotenoids, Algal Res. 5 (2014) 16-22, http://dx.doi.org/10.1016/j.algal.2014.05.001.

[64] P.P. Lamers, C.C.W. van de Laak, P.S. Kaasenbrood, J. Lorier, M. Janssen, R.C.H. De Vos, et al., Carotenoid and fatty acid metabolism in light-stressed Dunaliella salina, Biotechnol. Bioeng. 106 (2010) 638-648, http://dx.doi.org/10. 1002/bit.22725.

[65] S.N. Coesel, A.C. Baumgartner, L.M. Teles, A.A. Ramos, N.M. Henriques, L. Cancela, et al., Nutrient limitation is the main regulatory factor for carotenoid accumulation and for Psy and Pds steady state transcript levels in Dunaliella salina (Chlorophyta) exposed to high light and salt stress, Mar. Biotechnol. 10 (2008) 602-611, http://dx.doi.org/10.1007/s10126-008-9100-2.

[66] J. Seyfabadi, Z. Ramezanpour, Z. Amini Khoeyi, Protein, fatty acid, and pigment content of Chlorella vulgaris under different light regimes, J. Appl. Phycol. 23 (2011) 721-726, http://dx.doi.org/10.1007/s10811-010-9569-8.

[67] A.E. Solovchenko, I. Khozin-Goldberg, S. Didi-Cohen, Z. Cohen, M.N. Merzlyak, Effects of light and nitrogen starvation on the content and composition of carotenoids of the green microalga Parietochloris incisa, Russ. J. Plant Physiol. 55 (2008) 455-462, http://dx.doi.org/10.1134/S1021443708040043.

[68] J.a. Del Campo, J. Moreno, H. Rodríguez, M. Angeles Vargas, J. Rivas, M.G. Guerrero, Carotenoid content of chlorophycean microalgae: factors determining lutein accumulation in Muriellopsis sp. (Chlorophyta), J. Biotechnol. 76 (2000) 51-59, http://dx.doi.org/10.1016/S0168-1656(99)00178-9.

[69] J.F. Sánchez, J.M. Fernández, F.G. Acién, A. Rueda, J. Pérez-Parra, E. Molina, Influence of culture conditions on the productivity and lutein content of the new strain Scenedesmus almeriensis, Process Biochem. 43 (2008) 398-405, http://dx. doi.org/10.1016/j.procbio.2008.01.004.

[70] F. Ahmed, K. Fanning, M. Netzel, P.M. Schenk, Induced carotenoid accumulation in Dunaliella salina and Tetraselmis suecica by plant hormones and UV-C radiation, Appl. Microbiol. Biotechnol. 99 (2015) 9407-9416, http://dx.doi.org/10.1007/ s00253-015-6792-x.

[71] J.A. Del Campo, H. Rodríguez, J. Moreno, M.Á. Vargas, J. Rivas, M.G. Guerrero, Accumulation of astaxanthin and lutein in Chlorella zofingiensis (Chlorophyta), Appl. Microbiol. Biotechnol. 64 (2004) 848-854, http://dx.doi.org/10.1007/ 
s00253-003-1510-5.

[72] J. Camacho-Rodríguez, M.C. Cerón-García, J.M. Fernández-Sevilla, E. MolinaGrima, The influence of culture conditions on biomass and high value product generation by Nannochloropsis gaditana in aquaculture, Algal Res. 11 (2015) 63-73, http://dx.doi.org/10.1016/j.algal.2015.05.017.

[73] A. Solovchenko, A. Lukyanov, O. Solovchenko, S. Didi-Cohen, S. Boussiba, I. Khozin-Goldberg, Interactive effects of salinity, high light, and nitrogen starvation on fatty acid and carotenoid profiles in Nannochloropsis oceanica CCALA 804, Eur. J. Lipid Sci. Technol. 116 (2014) 635-644, http://dx.doi.org/10.1002/ ejlt.201300456.

[74] A. Gómez-Loredo, J. Benavides, M. Rito-Palomares, Growth kinetics and fucoxanthin production of Phaeodactylum tricornutum and Isochrysis galbana cultures at different light and agitation conditions, J. Appl. Phycol. 28 (2016) 849-860, http://dx.doi.org/10.1007/s10811-015-0635-0.

[75] I. Khozin-Goldberg, C. Bigogno, P. Shrestha, Z. Cohen, Nitrogen starvation induces the accumulation of arachidonic acid in the freshwater green alga Parietochloris incisa (Trebuxiophyceae), J. Phycol. 38 (2002) 991-994, http://dx.doi.org/10. 1046/j.1529-8817.2002.01160.x.

[76] E.T. Yu, F.J. Zendejas, P.D. Lane, S. Gaucher, B.A. Simmons, T.W. Lane, Triacylglycerol accumulation and profiling in the model diatoms Thalassiosira pseudonana and Phaeodactylum tricornutum (Baccilariophyceae) during starvation, J. Appl. Phycol. 21 (2009) 669-681, http://dx.doi.org/10.1007/s10811-0089400-y.

[77] C. Bigogno, I. Khozin-Goldberg, Z. Cohen, Accumulation of arachidonic acid-rich triacylglycerols in the microalga Parietochloris incisa (Trebuxiophyceae, Chlorophyta), Phytochemistry 60 (2002) 135-143, http://dx.doi.org/10.1016/ S0031-9422(02)00037-7.

[78] U. Iskandarov, I. Khozin-Goldberg, Z. Cohen, Identification and characterization of $\Delta 12, \Delta 6$, and $\Delta 5$ desaturases from the green microalga Parietochloris incisa, Lipids 45 (2010) 519-530, http://dx.doi.org/10.1007/s11745-010-3421-4.

[79] I. Khozin-Goldberg, P. Shrestha, Z. Cohen, Mobilization of arachidonyl moieties from triacylglycerols into chloroplastic lipids following recovery from nitrogen starvation of the microalga Parietochloris incisa, Biochim. Biophys. Acta - Mol. Cell Biol. Lipids. 1738 (2005) 63-71, http://dx.doi.org/10.1016/j.bbalip.2005.09.005.

[80] F. Mus, J.-P. Toussaint, K.E. Cooksey, M.W. Fields, R. Gerlach, B.M. Peyton, et al., Physiological and molecular analysis of carbon source supplementation and $\mathrm{pH}$ stress-induced lipid accumulation in the marine diatom Phaeodactylum tricornutum, Appl. Microbiol. Biotechnol. 97 (2013) 3625-3642, http://dx.doi.org/10. 1007/s00253-013-4747-7.

[81] A. Ben-Amotz, A. Shaish, M. Avron, Mode of action of the massively accumulated $\beta$-carotene of Dunaliella bardawil in protecting the alga against damage by excess irradiation, Plant Physiol. 91 (1989) 1040-1043, http://dx.doi.org/10.1104/pp. 91.3.1040.

[82] B. Wang, A. Zarka, A. Trebst, S. Boussiba, Astaxanthin accumulation in Haematococcus pluvialis (Chlorophyceae) as an active photoprotective process under high irradiance, J. Phycol. 39 (2003) 1116-1124, http://dx.doi.org/10. 1111/j.0022-3646.2003.03-043.x.

[83] J. Liu, Z. Sun, H. Gerken, Z. Liu, Y. Jiang, F. Chen, Chlorella zofingiensis as an alternative microalgal producer of astaxanthin: biology and industrial potential, Mar. Drugs. 12 (2014) 3487-3515, http://dx.doi.org/10.3390/md12063487.

[84] H. Wu, T. Li, G. Wang, S. Dai, H. He, W. Xiang, A comparative analysis of fatty acid composition and fucoxanthin content in six Phaeodactylum tricornutum strains from different origins, Chin. J. Oceanol. Limnol. 34 (2016) 391-398, http://dx.doi.org/ 10.1007/s00343-015-4325-1.

[85] D. Pelah, A. Sintov, E. Cohen, The effect of salt stress on the production of canthaxanthin and astaxanthin by Chlorella zofingiensis grown under limited light intensity, World J. Microbiol. Biotechnol. 20 (2004) 483-486, http://dx.doi.org/ 10.1023/B:WIBI.0000040398.93103.21.

[86] M. Orosa, J.F. Valero, C. Herrero, J. Abalde, Comparison of the accumulation of astaxanthin in Haematococcus pluvialis and other greenmicroalgae under $\mathrm{N}$ starvation and high light conditions, Biotechnol. Lett. 23 (2001) 1079-1085, http://dx.doi.org/10.1023/A:1010510508384.

[87] A.J. Klok, D.E. Martens, R.H. Wijffels, P.P. Lamers, Simultaneous growth and neutral lipid accumulation in microalgae, Bioresour. Technol. 134 (2013) 233-243, http://dx.doi.org/10.1016/j.biortech.2013.02.006.

[88] J. Pruvost, G. Van Vooren, G. Cogne, J. Legrand, Investigation of biomass and lipids production with Neochloris oleoabundans in photobioreactor, Bioresour. Technol. 100 (2009) 5988-5995, http://dx.doi.org/10.1016/j.biortech.2009.06. 004.

[89] M. Mitra, S.K. Patidar, B. George, F. Shah, S. Mishra, A euryhaline Nannochloropsis gaditana with potential for nutraceutical (EPA) and biodiesel production, Algal Res. 8 (2015) 161-167, http://dx.doi.org/10.1016/j.algal.2015.02.006.

[90] G. Van Vooren, F. Le Grand, J. Legrand, S. Cuiné, G. Peltier, J. Pruvost Investigation of fatty acids accumulation in Nannochloropsis oculata for biodiesel application, Bioresour. Technol. 124 (2012) 421-432, http://dx.doi.org/10.1016/ j.biortech.2012.08.009.

[91] X. Huang, Z. Huang, W. Wen, J. Yan, Effects of nitrogen supplementation of the culture medium on the growth, total lipid content and fatty acid profiles of three microalgae (Tetraselmis subcordiformis, Nannochloropsis oculata and Pavlova viridis), J. Appl. Phycol. 25 (2013) 129-137, http://dx.doi.org/10.1007/s10811-0129846-9.

[92] R. Radakovits, R.E. Jinkerson, A. Darzins, M.C. Posewitz, Genetic engineering of algae for enhanced biofuel production, Eukaryot. Cell 9 (2010) 486-501, http:// dx.doi.org/10.1128/EC.00364-09.

[93] E.C. Goncalves, A.C. Wilkie, M. Kirst, B. Rathinasabapathi, Metabolic regulation of triacylglycerol accumulation in the green algae: identification of potential targets for engineering to improve oil yield, Plant Biotechnol. J. 14 (2016) 1649-1660, http://dx.doi.org/10.1111/pbi.12523.
[94] S. Bellou, I.-E. Triantaphyllidou, D. Aggeli, A.M. Elazzazy, M.N. Baeshen, G. Aggelis, Microbial oils as food additives: recent approaches for improving microbial oil production and its polyunsaturated fatty acid content, Curr. Opin Biotechnol. 37 (2016) 24-35, http://dx.doi.org/10.1016/j.copbio.2015.09.005.

[95] M.L. Hamilton, J. Warwick, A. Terry, M.J. Allen, J.A. Napier, O. Sayanova, Towards the industrial production of omega-3 long chain polyunsaturated fatty acids from a genetically modified diatom Phaeodactylum tricornutum, PLoS One 10 (2015) e0144054, , http://dx.doi.org/10.1371/journal.pone.0144054.

[96] T.G. Dunahay, E.E. Jarvis, P.G. Roessler, Genetic transformation of the diatoms Cyclotella cryptica and Navicula saprophila, J. Phycol. 31 (1995) 1004-1012, http://dx.doi.org/10.1111/j.0022-3646.1995.01004.x.

[97] H.-J. Hsieh, C.-H. Su, L.-J. Chien, Accumulation of lipid production in Chlorella minutissima by triacylglycerol biosynthesis-related genes cloned from Saccharomyces cerevisiae and Yarrowia lipolytica, J. Microbiol. 50 (2012) 526-534, http://dx.doi.org/10.1007/s12275-012-2041-5.

[98] M.H. Liang, J.G. Jiang, Advancing oleaginous microorganisms to produce lipid via metabolic engineering technology, Prog. Lipid Res. 52 (2013) 395-408, http://dx. doi.org/10.1016/j.plipres.2013.05.002.

[99] Sanjaya, R. Miller, T.P. Durrett, D.K. Kosma, T.A. Lydic, B. Muthan, et al., Altered lipid composition and enhanced nutritional value of Arabidopsis leaves following introduction of an algal diacylglycerol acyltransferase 2, Plant Cell. 25 (2013) 677-693, http://dx.doi.org/10.1105/tpc.112.104752.

[100] A.F. Talebi, M. Tohidfar, A. Bagheri, S.R. Lyon, K. Salehi-ashtiani, M. Tabatabaei, Manipulation of Carbon Flux Into Fatty Acid Biosynthesis Pathway in Dunaliella salina Using AccD and ME Genes to Enhance Lipid Content and to Improve Produced Biodiesel Quality, 3 (2014), pp. 91-97.

[101] J. Xue, Y.-F. Niu, T. Huang, W.-D. Yang, J.-S. Liu, H.-Y. Li, Genetic improvement of the microalga Phaeodactylum tricornutum for boosting neutral lipid accumulation, Metab. Eng. 27 (2015) 1-9, http://dx.doi.org/10.1016/j.ymben.2014.10.002.

[102] Y. Kaye, O. Grundman, S. Leu, A. Zarka, B. Zorin, S. Didi-Cohen, et al., Metabolic engineering toward enhanced LC-PUFA biosynthesis in Nannochloropsis oceanica: overexpression of endogenous $\Delta 12$ desaturase driven by stress-inducible promoter leads to enhanced deposition of polyunsaturated fatty acids in TAG, Algal Res. 11 (2015) 387-398, http://dx.doi.org/10.1016/j.algal.2015.05.003.

[103] Y.-F. Niu, M.-H. Zhang, D.-W. Li, W.-D. Yang, J.-S. Liu, W.-B. Bai, et al., Improvement of neutral lipid and polyunsaturated fatty acid biosynthesis by overexpressing a type 2 diacylglycerol acyltransferase in marine diatom Phaeodactylum tricornutum, Mar. Drugs. 11 (2013) 4558-4569, http://dx.doi.org/ $10.3390 / \mathrm{md} 11114558$

[104] M. La Russa, C. Bogen, A. Uhmeyer, A. Doebbe, E. Filippone, O. Kruse, et al., Functional analysis of three type-2 DGAT homologue genes for triacylglycerol production in the green microalga Chlamydomonas reinhardtii, J. Biotechnol. 162 (2012) 13-20, http://dx.doi.org/10.1016/j.jbiotec.2012.04.006.

[105] M. Iwai, K. Ikeda, M. Shimojima, H. Ohta, Enhancement of extraplastidic oil synthesis in Chlamydomonas reinhardtii using a type-2 diacylglycerol acyltransferase with a phosphorus starvation-inducible promoter, Plant Biotechnol. J. 12 (2014) 808-819, http://dx.doi.org/10.1111/pbi.12210.

[106] M.L. Hamilton, R.P. Haslam, J.A. Napier, O. Sayanova, Metabolic engineering of Phaeodactylum tricornutum for the enhanced accumulation of omega-3 long chain polyunsaturated fatty acids, Metab. Eng. 22 (2014) 3-9, http://dx.doi.org/10. 1016/j.ymben.2013.12.003.

[107] B.F. Cordero, I. Couso, R. León, H. Rodríguez, M.Á. Vargas, Enhancement of carotenoids biosynthesis in Chlamydomonas reinhardtii by nuclear transformation using a phytoene synthase gene isolated from Chlorella zofingiensis, Appl. Microbiol. Biotechnol. 91 (2011) 341-351, http://dx.doi.org/10.1007/s00253011-3262-y.

[108] N. Anila, D.P. Simon, A. Chandrashekar, G.A. Ravishankar, R. Sarada, Metabolic engineering of Dunaliella salina for production of ketocarotenoids, Photosynth. Res. 127 (2016) 321-333, http://dx.doi.org/10.1007/s11120-015-0188-8.

[109] R. León, I. Couso, E. Fernández, Metabolic engineering of ketocarotenoids biosynthesis in the unicelullar microalga Chlamydomonas reinhardtii, J. Biotechnol. 130 (2007) 143-152, http://dx.doi.org/10.1016/j.jbiotec.2007.03.005.

[110] A.K. Bajhaiya, J. Ziehe Moreira, J.K. Pittman, Transcriptional engineering of microalgae: prospects for high-value chemicals, Trends Biotechnol. (2016) 1-4 In Press http://dx.doi.org/10.1016/j.tibtech.2016.06.001.

[111] U. Iskandarov, I. Khozin-Goldberg, Z. Cohen, Selection of a DGLA-producing mutant of the microalga Parietochloris incisa: I. Identification of mutation site and expression of VLC-PUFA biosynthesis genes, Appl. Microbiol. Biotechnol. 90 (2011) 249-256, http://dx.doi.org/10.1007/s00253-010-3005-5.

[112] M.F. Montero, M. Aristizábal, G. García Reina, Isolation of high-lipid content strains of the marine microalga Tetraselmis suecica for biodiesel production by flow cytometry and single-cell sorting, J. Appl. Phycol. 23 (2011) 1053-1057, http:// dx.doi.org/10.1007/s10811-010-9623-6.

[113] D.K.Y. Lim, H. Schuhmann, K. Sharma, P.M. Schenk, Isolation of high-lipid Tetraselmis suecica strains following repeated UV-C mutagenesis, FACS, and high throughput growth selection, BioEnergy Res. 8 (2015) 750-759, http://dx.doi. org/10.1007/s12155-014-9553-2.

[114] T.T.Y. Doan, J.P. Obbard, Enhanced intracellular lipid in Nannochloropsis sp. via random mutagenesis and flow cytometric cell sorting, Algal Res. 1 (2012) 17-21, http://dx.doi.org/10.1016/j.algal.2012.03.001.

[115] K. Manandhar-Shrestha, M. Hildebrand, Development of flow cytometric procedures for the efficient isolation of improved lipid accumulation mutants in a Chlorella sp. microalga, J. Appl. Phycol. 25 (2013) 1643-1651, http://dx.doi.org/ 10.1007/s10811-013-0021-8.

[116] H. Mendoza, A. de la Jara, K. Freijanes, L. Carmona, A.A. Ramos, V. de Sousa Duarte, et al., Characterization of Dunaliella salina strains by flow cytometry: a new approach to select carotenoid hyperproducing strains, Electron. J. Biotechnol. 11 (2008) 1-13, http://dx.doi.org/10.2225/vol11/issue4-fulltext-2. 